\title{
REVIEW
}

\section{Astrochemistry as the basics of Astrobiology: from simplest molecules to bioindicatorsonexoplanets surfaces}

\author{
A.G. Yeghikyan \\ NAS RA V. Ambartsumian Byurakan Astrophysical Observatory (BAO) \\ e-mail: ayarayeg@gmail.com
}

\begin{abstract}
The problem of the origin of Life is discussed from the astrophysical point of view. Most biologists and geologists up to the present time believe that Life was originated on the Earth in some initial natural chemical pre-reactors, where a mixture of water, ammonia, methane containing species and some other substances, under the influence of an energy source like, e.g. lightning, turned into quite complex compounds such as amino acids and complex hydrocarbons. In fact, under conditions of the primordial Earth, it is not possible to obtain such pre-biological molecules by not-bio-chemical methods, as discussed in this paper. Instead, an astrophysical view of the problem of the origin of Life on the Earth is proposed and it is recalled that the biological evolution on the Earth was preceded by the chemical evolution of complex chemical compounds, mostly under extraterrestrial conditions, where it is only possible to form optically active amino acids, sugars and heavy hydrocarbons necessary for constructing the first pre-biomolecules. Then, according to a widespread point of view, they were brought to Earth by comets and dust between 4.5 and 3.8 billion years ago. Some part of the matter of comets landed unchanged during grazing collisions. Prebiotic complexes on the surface of the planet participate in the formation of a specific cover with a reflective spectrum (or color index), whose characteristic details can be tried to reveal by observation. The most promising bio-indicators at present are optically active amino acids and their derivatives, however, the existing observational capabilities are insufficient to identify them. More promising as (pre)biomarkers are the heavy hydrocarbons discussed in this article, in particular bitumen and isoprene hydrocarbons.
\end{abstract}

Keywords: origin of life, chemical compounds in space, ice covers of dust grains, CR and UV induced radiation chemical polymerization of ices, chiral species, bio-indicators.

\section{Introduction}

Most biologists and geologists up to the present time believe that Life was originated on the Earth (Campbell et al. 2010). In fact, under conditions of the 
primordial Earth, it is not possible to obtain pre-biological molecules by biochemical methods, as discussed in this paper. The origin of pre-life can be described in general terms as a kind of process of development from simple to complex, that is from simple chemical molecules to complex molecular species. The case is that there is a generally accepted point of view by astrophysicists that a biological evolution on the Earth was preceded by a period of chemical evolution during which formation and organization of pre-bio-organic compounds were accomplished - predominantly under extraterrestrial conditions. It should be evident that Life as we know it clearly originated in the same way that everything originates, step by step.Let's discuss these steps of pre-biological evolution from the astrophysical point of view.

\section{Steps of pre-biological evolution}

\section{Step 1 - just chemistry of simple molecules}

We limit our consideration by last 10 billion years when dust particles were abundant with gas to dust mass ratio of 100 (sometimes up to 1000) to 1 (Ehrenfreund et al. 2002). In that time in interstellar molecular clouds behind the photo-dissociation region the simplest but the most abundant molecular hydrogen $\mathrm{H}_{2}$ may effectively originate on dust grain surfaces with time-scale (Ehrenfreund et al. 2002)

$$
t\left(\mathrm{H}_{2}\right)=\frac{1.5 \cdot 10^{9}}{n} \mathrm{yr},
$$

that is in re-stellar cores with $n \geq 10^{6} \mathrm{~cm}^{-3}$ then $t\left(\mathrm{H}_{2}\right) \leq 1500 \mathrm{yr}$. But under conditions of unshielded interstellar medium (ISM) molecules will be destroyed in (Williams, Viti, 2013; Yamamoto, 2017)

$t($ photodiss. $)=\frac{1}{k_{0}(0) \mathrm{s}^{-1}}=\frac{10^{9}-10^{11}}{3 \cdot 10^{7}} \mathrm{yr} \cong 33-3300$ years,

where $k_{0}(0)$ is related with the characteristic time of the photo-dissociation in the ISM. Thus, molecules may be accumulated only inside of interstellar clouds and proto-stellar disks. Typical values of interstellar cloud parameters are given in Fig. 1. Densities of protoplanetary regions are much higher, about $10^{10} \mathrm{~cm}^{-3}$, at the same time for the protosolar nebula 4.5 billion years ago temperatures vary between $800 \mathrm{~K}$ (the proto Earth orbit) and less than $100 \mathrm{~K}$ beyond the proto Mars or to be more correct beyond of the "snow line"(Ehrenfreund et al. 2002). It clearly explains why there were no volatiles on the proto-Earth and that probably they were delivered by comets between 4.5-3.8 billion years ago (a heavy bombardment period). In particular, one can speculate about water for oceans and molecular nitrogen and carbon dioxide for atmosphere, and besides modern values of $\mathrm{D} / \mathrm{H}$ of oceans coincidence with that of mixture of $2 / 3$ from comets and $1 / 3$ of volcano waters (ibid). 


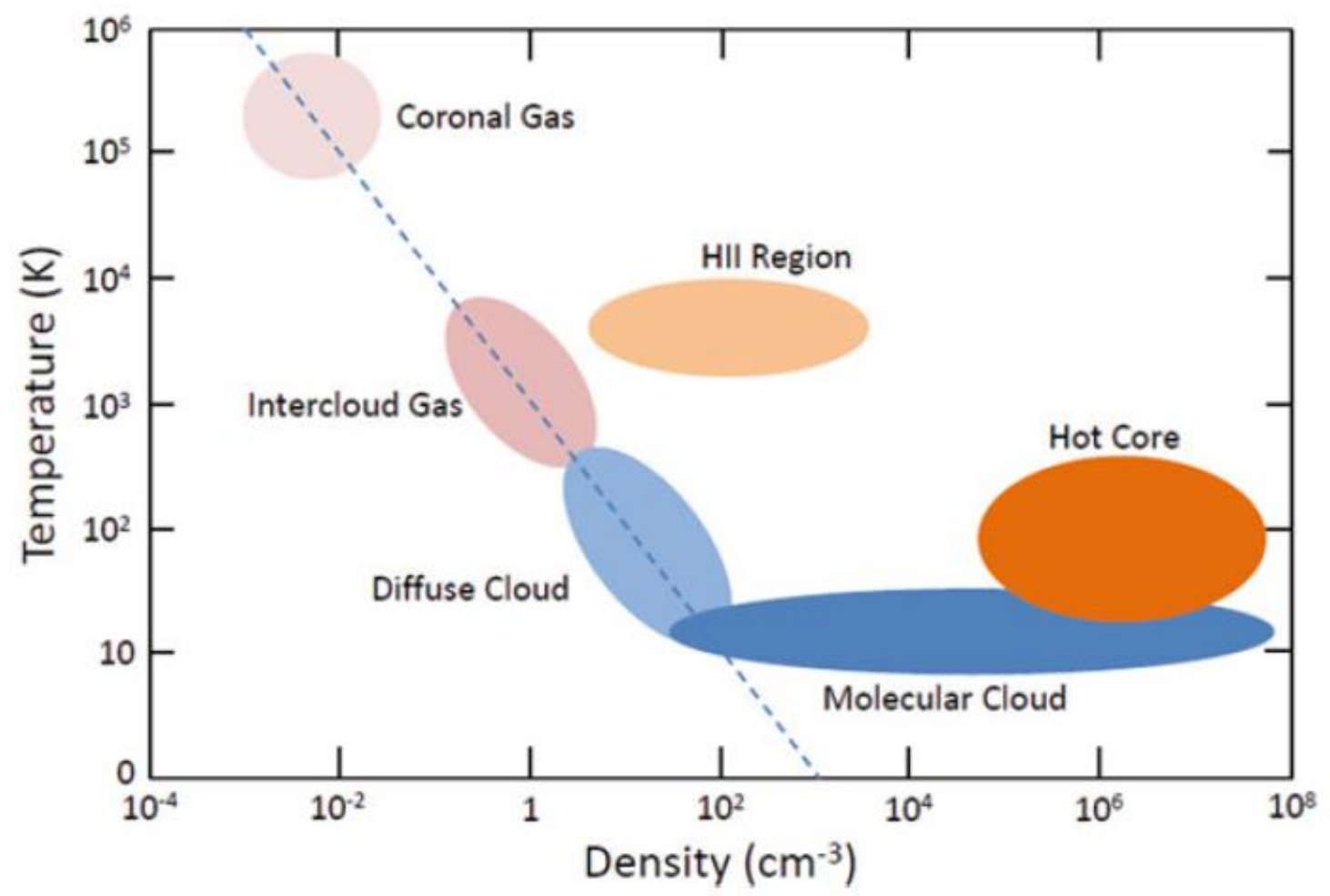

Figure 1.Temperature-density diagram of interstellar clouds. The dashed line indicates the constantpressure line, that is $n k T=$ const, or (density) $\cdot k \cdot($ Temperature $)=$ const. The diffuse interstellar medium is in pressure equilibrium (adopted from Yamamoto 2017).

Till 2018 almost 200 molecules have been detected in the Galaxy and 61 molecules in other galaxies (Table 1) (Muller et al. 2001, 2008; Yeghikyan, 2016a,b and references therein).

\section{Step 2 - dust and ice covers of dust grains.}

Dust grains come now with $\mathrm{SN}$ ejections and $\mathrm{AGB}$ winds.Initial sizes of graphite and/or silicate cores are of $\sim 0.01 \mu$, on which $\mathrm{H}_{2} \mathrm{O}, \mathrm{CO}, \mathrm{CO}_{2}, \mathrm{CH}_{4}, \mathrm{NH}_{3}, \mathrm{CH}_{3} \mathrm{OH}, \mathrm{HAC}$ (hydrogenated amorphous carbon) and other icy mantles grow up to sizes of $\sim 0.1 \mu$.Time-scales for dust growth in a dense cold medium (Ehrenfreund et al. 2002; Williams, Viti, 2013) ist $\sim \frac{3 \cdot 10^{9}}{n}$ years, which means a rapid growth in the star formation regions with pre-stellar clouds. The key reactions in astrochemistry include: (a) radiative association; (b) three-body reactions; (c) neutral exchanges; (d) ionmolecule reactions; (e) recombination; ( $f$ ) negative ion reactions; $(g)$ condensation reactions; (h) surface reactions; (i) especially important for biomolecules carbon insertion reactions; $(j)$ aggregation of dust grains and large molecules, as presented in Fig. 2 (Ehrenfreund et al. 2002; Williams, Viti, 2013; Yamamoto, 2017). 
Table 1. Molecules found in ISM (based on the Cologne Database for Molecular Spectroscopy, Muller et al. 2001, 2008).

Simple neutral molecules

$\mathrm{H}_{2}$, CH, CN, CO, HCl, NH, NO, NS, OH, PN, SO, SiO, SiS, CS, HF, O 2 , SH, $\mathrm{CH}_{2}, \mathrm{HCN}, \mathrm{HCO}$, $\mathrm{H}_{2} \mathrm{O}, \mathrm{H}_{2} \mathrm{~S}, \mathrm{HNC}, \mathrm{HNO}, \mathrm{N}_{2} \mathrm{O}, \mathrm{OCS}, \mathrm{SO}_{2}, \mathrm{CO}_{2}, \mathrm{NH}_{2}, \mathrm{HO}_{2}, \mathrm{NH}_{3}, \mathrm{H}_{2} \mathrm{CO}, \mathrm{H}_{2} \mathrm{CS}, \mathrm{CH}_{3}, \mathrm{H}_{2} \mathrm{O}_{2}, \mathrm{CH}_{4}$ Ionic species

(Cation)

$\mathrm{CH}^{+}, \mathrm{CO}^{+}, \mathrm{SO}^{+}, \mathrm{CF}^{+}, \mathrm{OH}^{+}, \mathrm{SH}^{+}, \mathrm{HCl}^{+}, \mathrm{ArH}^{+}, \mathrm{HCO}^{+}, \mathrm{HCS}^{+}, \mathrm{HOC}^{+}, \mathrm{N}_{2} \mathrm{H}^{+}, \mathrm{H}_{3}{ }^{+}, \mathrm{H}_{2} \mathrm{O}^{+}, \mathrm{H}_{2} \mathrm{Cl}^{+}$, $\mathrm{OH}_{3}{ }^{+}, \mathrm{HCNH}^{+}, \mathrm{HCO}_{2}{ }^{+}, \mathrm{C}_{3} \mathrm{H}^{+}, \mathrm{H}_{2} \mathrm{COH}^{+}, \mathrm{NH}_{4}{ }^{+}, \mathrm{H}_{2} \mathrm{NCO}^{+}, \mathrm{HC}_{3} \mathrm{NH}^{+}$

\begin{tabular}{|c|}
\hline (Anion) \\
\hline $\mathrm{C}_{4} \mathrm{H}^{-}, \mathrm{C}_{6} \mathrm{H}^{-}, \mathrm{C}_{8} \mathrm{H}$ \\
\hline Carbon-chain molecules and their isomers \\
\hline $\begin{array}{l}\mathrm{C}_{2}, \mathrm{C}_{3}, \mathrm{C}_{2} \mathrm{H}, \mathrm{C}_{2} \mathrm{O}, \mathrm{C}_{2} \mathrm{~S}, \mathrm{c}-\mathrm{C}_{3} \mathrm{H}, \mathrm{l}-\mathrm{C}_{3} \mathrm{H}, \mathrm{C}_{3} \mathrm{~N}, \mathrm{C}_{3} \mathrm{O}, \mathrm{C}_{3} \mathrm{~S}, \mathrm{C}_{2} \mathrm{H}_{2}, \mathrm{C}_{5}, \mathrm{C}_{4} \mathrm{H}, 1-\mathrm{C}_{3} \mathrm{H}_{2}, \mathrm{c}-\mathrm{C}_{3} \mathrm{H}_{2}, \mathrm{HC}_{3} \mathrm{~N}, \\
\mathrm{HCCNC}^{2} \mathrm{HNC}_{3}, \mathrm{C}_{5} \mathrm{H}, 1-\mathrm{C}_{4} \mathrm{H}_{2}, \mathrm{C}_{5} \mathrm{~N}, \mathrm{C}_{6} \mathrm{H}, \mathrm{CH}_{3} \mathrm{CCH}, \mathrm{HC}_{5} \mathrm{~N}, \mathrm{CH}_{3} \mathrm{C}_{3} \mathrm{~N}, \mathrm{C}_{6} \mathrm{H}_{2}, \mathrm{CH}_{2} \mathrm{CCHCN}, \\
\mathrm{CH}_{3} \mathrm{C}_{4} \mathrm{H}, \mathrm{HC}_{7} \mathrm{~N}, \mathrm{CH}_{3} \mathrm{C}_{5} \mathrm{~N}, \mathrm{HC}_{9} \mathrm{~N}, \mathrm{CH}_{3} \mathrm{C}_{6} \mathrm{H}, \mathrm{HC}_{11} \mathrm{~N}\end{array}$ \\
\hline Complex organic molecules \\
\hline $\begin{array}{l}\mathrm{HCOOH}, \mathrm{CH}_{2} \mathrm{CO}, \mathrm{CH}_{3} \mathrm{CN}, \mathrm{CH}_{3} \mathrm{NC}, \mathrm{CH}_{3} \mathrm{OH}, \mathrm{CH}_{3} \mathrm{SH}, \mathrm{HC}_{2} \mathrm{CHO}, \mathrm{c}-\mathrm{C}_{3} \mathrm{H}_{2} \mathrm{O}, \mathrm{CH}_{2} \mathrm{CNH}, \\
\mathrm{HNCHCN}, \mathrm{CH}_{2} \mathrm{CHCN}, \mathrm{CH}_{3} \mathrm{CHO}_{2} \mathrm{CH}_{3} \mathrm{NH}_{2}, \mathrm{c}-\mathrm{C}_{2} \mathrm{H}_{4} \mathrm{O}, \mathrm{H}_{2} \mathrm{CCHOH}, \mathrm{HCOOCH}_{3}, \mathrm{CH}_{3} \mathrm{COOH} \text {, } \\
\mathrm{CH}_{2} \mathrm{OHCHO}, \mathrm{CH}_{2} \mathrm{CHCHO}, \mathrm{NH}_{2} \mathrm{CH}_{2} \mathrm{CN}, \mathrm{CH}_{3} \mathrm{CHNH}_{2} \mathrm{CH}_{3} \mathrm{CH}_{2} \mathrm{CN},\left(\mathrm{CH}_{3}\right)_{2} \mathrm{O}, \mathrm{CH}_{3} \mathrm{CH}_{2} \mathrm{OH}, \\
\mathrm{CH}_{3} \mathrm{CONH}_{2}, \mathrm{C}_{3} \mathrm{H}_{6}, \mathrm{CH}_{3} \mathrm{CH}_{2} \mathrm{SH},\left(\mathrm{CH}_{3}\right)_{2} \mathrm{CO},\left(\mathrm{CH}_{2} \mathrm{OH}\right)_{2}, \mathrm{CH}_{3} \mathrm{CH}_{2} \mathrm{CHO}, \mathrm{C}_{2} \mathrm{H}_{5} \mathrm{OCCHO}, \\
\mathrm{CH}_{3} \mathrm{OCOCH}_{3}, \mathrm{C}_{2} \mathrm{H}_{5} \mathrm{OCH}_{3}, \mathrm{n}-\mathrm{C}_{3} \mathrm{H}_{7} \mathrm{CN}\end{array}$ \\
\hline
\end{tabular}

Other molecules

FeO, $\mathrm{HNCO}, \mathrm{HNCS}, \mathrm{H}_{2} \mathrm{CN}, \mathrm{HCNO}, \mathrm{HOCN}, \mathrm{HSCN}, \mathrm{CH}_{2} \mathrm{CN}, \mathrm{H}_{2} \mathrm{CNH}, \mathrm{NH}_{2} \mathrm{CN}, \mathrm{HCOCN}$, $\mathrm{HNCNH}, \mathrm{CH}_{3} \mathrm{O}, \mathrm{NH}_{2} \mathrm{CHO}$

By means of different kinds of interaction of molecular particles with electromagnetic and corpuscular radiation and with each other resulting molecules can become more complicated, especially if the reactions take place on the surface of grains (Fig. 3). Besidesgrain surfacechemistryis very important for origin of $\mathrm{H}, \mathrm{C}, \mathrm{O}, \mathrm{N}$ containing complex ices in star formation regions (Yeghikyan et al. 2001; Ehrenfreund et al. 2002; Williams, Viti, 2013; Yamamoto, 2017). 
(a) radiative association

reverse reaction - photodissociation
A + B $\rightarrow$
AB
$+\sum h v^{2}=$ or $\sum h v^{2}=+$
AB
$\rightarrow$ B $+A$

(b) three-body reactions

reverse reaction - collisional dissociation
(A)
+ B + M
$\rightarrow$
AB +
(M) or
M $+A B$
$\rightarrow M+B+A$

(c) neutral exchanges

$$
\text { AB }+\mathrm{D} \rightarrow \mathrm{BD}+\mathrm{A}
$$

(e) recombination reaction

(e1) radiative recombination (atomic)

$$
\mathrm{A}^{+}+\mathrm{C}^{-} \rightarrow \mathrm{A}+\mathrm{Zhv}_{\mathrm{N}}^{\mathrm{h}} \mathrm{h}
$$

(e2) radiative association

$$
\begin{gathered}
e^{-}+\mathrm{B}+\mathrm{M} \rightarrow \mathrm{B}^{-}+\mathrm{M} \\
\mathrm{e}^{-}+\mathrm{A} \rightarrow \mathrm{A}^{-}
\end{gathered}
$$

(e2) dissociative recombination (molecular)

$$
\begin{aligned}
& \mathrm{AB}+e^{-} \longrightarrow \mathrm{B}^{-}+\mathrm{A} \\
& \mathrm{AB}^{+}+\mathrm{e}^{-} \longrightarrow \mathrm{B}+\mathrm{A}
\end{aligned}
$$

(d) ion-molecule reactions

$$
\text { AB }+\mathrm{D}^{+} \rightarrow \mathrm{BD}^{+}+\mathrm{A}
$$

charge transfer reactions

$$
\text { AB }+\mathrm{D}^{+} \rightarrow \mathrm{AB}^{+}+\mathrm{D}
$$

(f) negative ion reactions

$$
\begin{aligned}
& A+A^{-} \rightarrow A_{2}+e^{-} \\
& \text {A }+B^{-} \rightarrow A B+e^{-}
\end{aligned}
$$

(g) condensation reactions

AB (gas phase) $\longrightarrow$ AB (solid)

\section{(h) surface reactions}

(h1) heterogeneous catalysis

(h2) adsorption or

(h3) thermal desorption

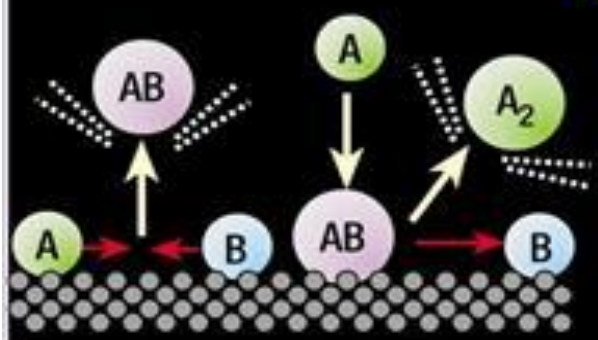

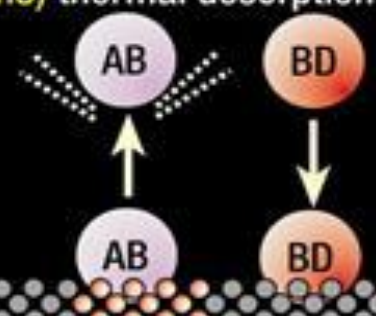

(h4) UV/ion/electron impact

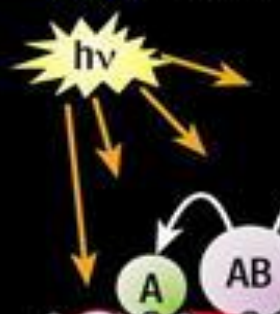

$\mathrm{B}_{2} \mathrm{D}$

(i) carbon insertion reactions, e.g.

$\mathrm{C}^{+}+\mathrm{CH}_{4} \rightarrow \mathrm{C}_{2} \mathrm{H}_{2}^{+}+\mathrm{H}_{2} \stackrel{+\mathrm{e}^{-}}{\longrightarrow} \mathrm{C}_{2} \mathrm{H}+\mathrm{H} \stackrel{+\mathrm{C}^{+}}{\longrightarrow} \mathrm{C}_{3}^{+}+\mathrm{H}$

(j) dust grain aggregation

(j) dust grain aggregation

Figure 2. The key reactions in astrochemistry (Fraser et al. 2002). reverse reaction - splintering of grains

or $\mathrm{M}^{+}+3 \mathrm{~g}+\mathrm{PAH}$ 


\section{Graine surface chemistry is very important}

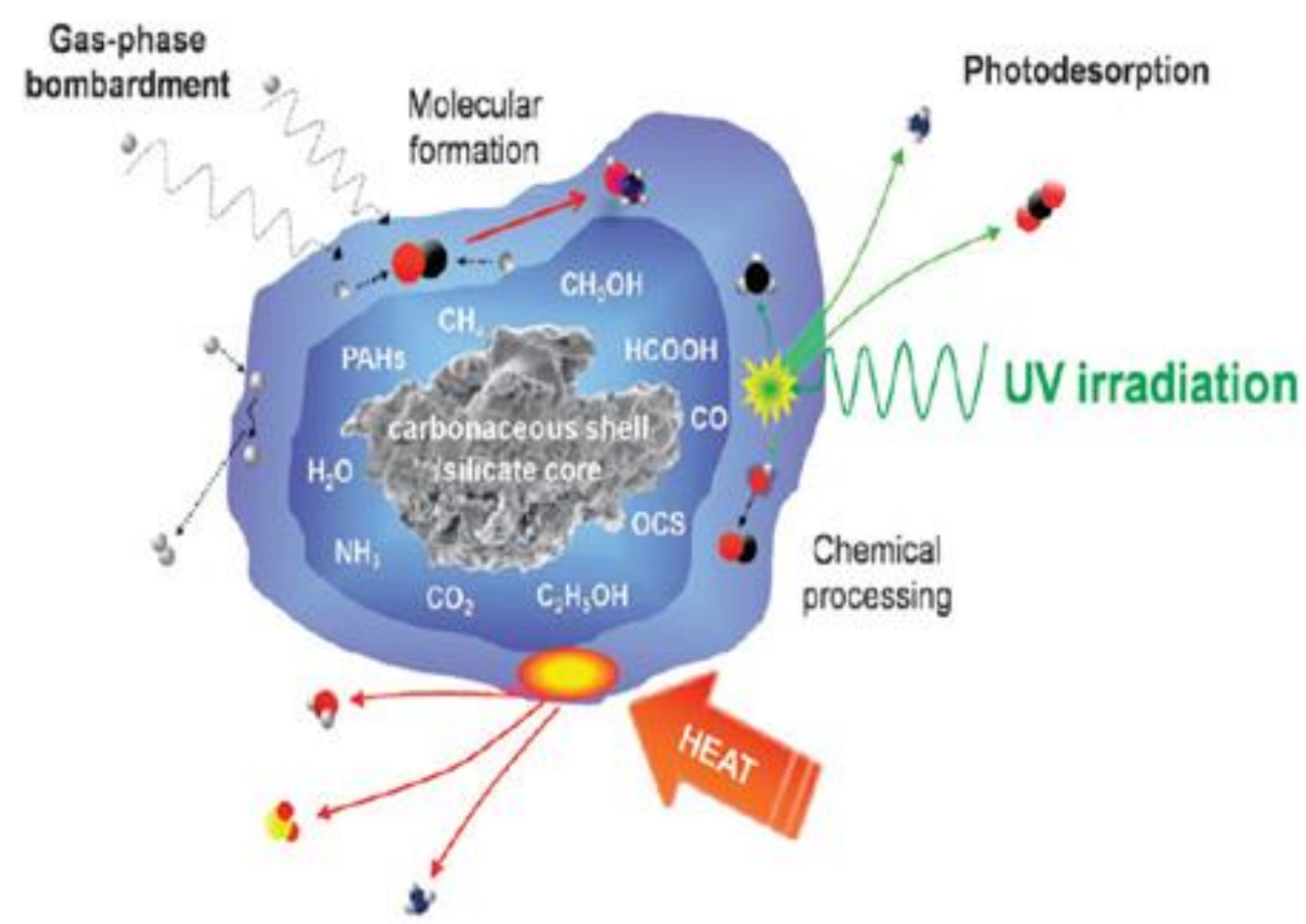

Figure 3.Different kinds of surface reactions (adopted from Yamamoto 2017)

Usually it is assumed that all gas-phase species, other than $\mathrm{H}_{2}$ and $\mathrm{He}$, stick to the surfaces of dust grains when they collide with them, with a specific sticking probability; $\mathrm{H}$ atoms are assumed to be converted to $\mathrm{H}_{2}$ and ejected from the surface as $\mathrm{H}_{2}$. The sticking probability is a hard-to-determine quantity and frequently it is assumed that all species stick with the same efficiency, so that the freeze-out rate is determined solely by the thermal speeds of the different species. In short, the loss of species by freeze-out is defined through a parameter, $S$, for which $S=1$ implies that there is a distribution of grain sizes similar to that defined by standard way (Williams, Viti 2013) and that sticking probabilities are unity. In fact, assuming $S=0.1$ in nearly all estimations is not bad approximation. This reduction in $S$ is an attempt to take account of the larger grain sizes that have been inferred from extinction measurements to exist in denser interstellar gas, since larger grains imply less surface area per unit mass. The fundamental assumption here is that, on sticking to grain surfaces, any species that can be hydrogenated at low temperature will be saturated with hydrogen and retained on the dust grain surface. Thus oxygen is assumed to be converted to water, nitrogen to ammonia, and, particularly, carbon to methane (Yeghikyan et al. 2001, and references therein). 
Table 2.The molecular universe (adopted from Fraser et al. 2002).A comparison of observed molecular abundances in interstellar and cometary systems.

A comparison of molecular abundances in interstellar ices and cometary systems (adapted from Crovisier 1998).

\begin{tabular}{|c|c|c|c|c|c|}
\hline \multirow[b]{3}{*}{ Molecule } & \multicolumn{2}{|c|}{ Cometary ices } & \multicolumn{3}{|c|}{ Interstellar ices } \\
\hline & Hale-Bopp & Other comets & Dark clouds & Embe & YSOs \\
\hline & & & (Elias 16) & $\begin{array}{l}\text { Low Mass } \\
\text { (Elias 29) }\end{array}$ & $\begin{array}{c}\text { High Mass } \\
\text { (W/33a) }\end{array}$ \\
\hline $\mathrm{H}_{2} \mathrm{O}$ & 100 & 100 & 100 & 100 & 100 \\
\hline $\mathrm{CO}$ & 20 & $6-30$ & 25 & 5.6 & 9 \\
\hline $\mathrm{CO}_{2}$ & $6-20$ & $2-10$ & 18 & 22 & 14 \\
\hline $\mathrm{CH}_{4}$ & 0.6 & 0.7 & $1-2$ & $<1.6$ & 2 \\
\hline $\mathrm{CH}_{3} \mathrm{OH}$ & 2 & $1-7$ & $<3$ & $<4$ & 22 \\
\hline $\mathrm{H}_{2} \mathrm{CO}$ & 1 & $0.2-1$ & $2-6 ?$ & - & $1.7-7$ \\
\hline ocs & 0.5 & 0.1 & 0.2 & $<0.08$ & 0.3 \\
\hline $\mathrm{NH}_{3}$ & $0.7-0.18$ & 0.5 & $<10$ & $<9.2$ & 15 \\
\hline $\mathrm{C}_{2} \mathrm{H}_{6}$ & 0.3 & 0.4 & - & - & - \\
\hline $\mathrm{HCOOH}$ & 0.06 & - & $3 ?$ & - & $0.4-2$ \\
\hline $\mathrm{OCN}^{-}=\mathrm{XCN}$ & - & - & $<2$ & 0.24 & $3-10$ \\
\hline $\mathrm{HCN}$ & 0.25 & $0.05-0.2$ & $0.5-10$ & - & $<3$ \\
\hline HNC & 0.04 & 0.01 & - & - & - \\
\hline HNCO & $0.06-0.1$ & 0.07 & - & - & - \\
\hline $\mathrm{C}_{2} \mathrm{H}_{2}$ & 0.1 & 0.5 & - & - & - \\
\hline $\mathrm{CH}_{3} \mathrm{CN}$ & 0.02 & 0.01 & - & - & - \\
\hline $\mathrm{HCOOCH}_{3}$ & 0.06 & - & - & - & - \\
\hline $\mathrm{HC}_{3} \mathrm{~N}$ & 0.02 & - & - & - & - \\
\hline $\mathrm{NH}_{2} \mathrm{CHO}$ & 0.01 & - & - & - & - \\
\hline $\mathrm{H}_{2} \mathrm{~S}$ & 1.5 & $0.2-1.5$ & - & - & - \\
\hline $\mathrm{H}_{2} \mathrm{CS}$ & 0.02 & - & - & - & - \\
\hline So & $0.2-0.8$ & - & - & - & - \\
\hline $\mathrm{SO}_{2}$ & 0.1 & - & - & - & - \\
\hline $\mathrm{O}_{3}$ & - & - & $<2$ & - & - \\
\hline $\mathrm{H}_{2}$ & $?$ & $?$ & 1 & $?$ & $?$ \\
\hline $\mathrm{N}_{2}$ & $?$ & $?$ & $?$ & $?$ & $?$ \\
\hline $\mathbf{O}_{2}$ & $?$ & $?$ & $?$ & $?$ & $?$ \\
\hline
\end{tabular}

Note that all abundances are expressed as a percentage as compared to the abundance of $\mathrm{H}_{2} \mathrm{O}$ ice. - indicates a current lack of information. ? indicates ice expected to be present but not observable.

\section{$\mathrm{H}, \mathrm{C}, \mathrm{O}, \mathrm{N}$ containing ices in SFR}

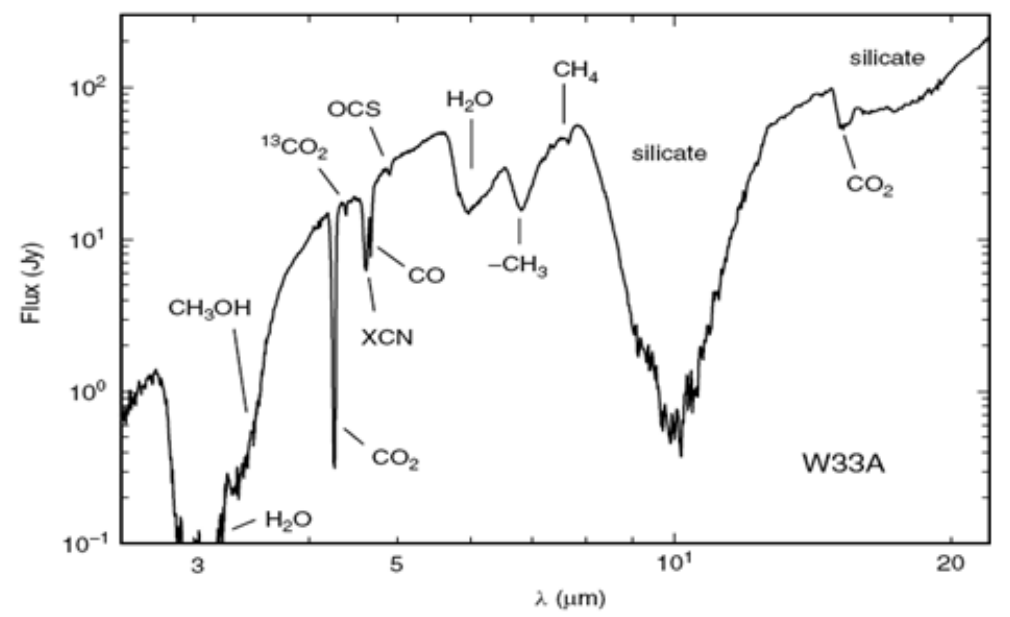

Figure 4. Ices as observed in SFR (adopted from Fraser et al. 2002) 


\section{Step 3 - complexization.}

Why ices are important ?A short answer is that complex species are more easily generated in solid state of ice mantles of dust grains if ultraviolet (UV, 6-13.6 eV) andcosmic rays $(C R, \geq 1 \mathrm{MeV})$ radiation fields are available. A mixture of realistic ice analogues like $\mathrm{H}_{2} \mathrm{O}: \mathrm{CH}_{3} \mathrm{OH}: \mathrm{NH}_{3}: \mathrm{CO}: \mathrm{CH}_{4}$ has produced heavy hydrocarbons (up to 30 $\mathrm{C}$ atoms per molecule) and aminoacids by UV and/or energetic particles processing in laboratory (Ehrenfreund et al. 2002; Fraser et al. 2002; Keheyan et al. 2004 and references therein).A possibility of radiation chemical transformation of ices under influence of realistic UV and CR souces were modeled and results were discussed in our works (Yeghikyan et al. 2001; Yeghikyan and Fahr, 2003,2004a,b,2006; Keheyan et al. 2004; Yeghikyan 2008,2009,2010,2011a,b, 2013a; Yeghikyan and Barsamyan, 2013, Yeghikyan 2013b, 2015, 2016a,b,2017).Also molecular symmetry may be broken easier in ices under molecular cloud conditions as compared with protoplanetary conditions (Ehrenfreund et al. 2002; Meierhenrich, 2008). UV and CRinduced solidphase radiation chemical polymerization (polycondensation) may produce complex species with time-scales about Kyrs Myrs - depending on duration of available processing.CR contribution known from laboratory experiments is the following: complexaliphatic $\leq \mathrm{C}_{29} \mathrm{H}_{60}$ ) and aromatic ( $\mathrm{PAH}, \leq \mathrm{C}_{24} \mathrm{H}_{12}$ - coronene) hydrocarbons have been synthesized in prebiotic simulation experiments by irradiation of solid $\mathrm{CH}_{4}$ with $7 \mathrm{MeV}$ protons and/or $\alpha$-particles(Yeghikyan et al. 2001; Yeghikyan, 2008, 2011, 2013; Yeghikyan and Barsamyan 2013, and references therein), in short radiation chemical polycondensation of methane by $\mathrm{MeV}$ protons and $\alpha$-particles. $\mathrm{A}$ radiation chemical yield of alkanes in such a process resulting with products like $\leq$ $\mathrm{C}_{29} \mathrm{H}_{60}$, is $Y \sim 1$ synth.mol /100 eV- a monomer fraction converted to oligomer: $Q \sim Y$. $D$ depending onDirradiation dose, $D_{\text {exp. }} \sim 6 \mathrm{eV} /$ molecule $(0.3 \mathrm{eV} /$ a.m.u.) (Yeghikyan et al. 2001 and references therein).Here a time processing available for irradiation is comparable with a collapsing time of 1.1 Myr (Yeghikyan et al. 2001).

Also UV radiation induced chemical transformation of ices was revealed in experiments (Yeghikyan, 2009,Yeghikyan, 2013aand references therein). A mixture of $\mathrm{H}_{2} \mathrm{O}: \mathrm{CH}_{3} \mathrm{OH}: \mathrm{NH}_{3}$ : $\mathrm{CO}(100: 50: 1: 1)$, irradiated by UV(at $15 \mathrm{~K}$ ) resulted with $\mathrm{C}_{\mathrm{n}} \mathrm{H}_{\mathrm{m}}$ ( $\mathrm{n} \leq$ 22)hydrocarbons, and other complex species, likehexamethylenetetramine, HMT $\mathrm{C}_{6} \mathrm{H}_{12} \mathrm{~N}_{4}$ (very close to aminoacids). Threshold doses in the experimentsfor fluxes $\sim 3$. $10^{4}$ photons $/ \mathrm{cm}^{2}$.s producing such specieshave been originating at doses of $D_{\text {exp. }} \sim 25$ $\mathrm{eV} /$ molecule $=1.4 \mathrm{eV} / \mathrm{a} \cdot \mathrm{m} . \mathrm{u}$.

Interestingly, glycolaldehydeand glycine were observed in hot molecular core (Fig. 5,6)(both were optically not active) (Beltran et al. 2009; Kuan et al. 2003). On the other handcarbon containing complex species revealed in meteorites contain aminoacids with enanthiomeric excess, and were optically active (Table 3) 
(Ehrenfreund et al. 2002; Meierheinrich 2008, and references therein)!l will discuss such a circumstance in Step 5 while now, in short, some details of the formation of glycolaldehyde on the surface of dust grains would be presented.

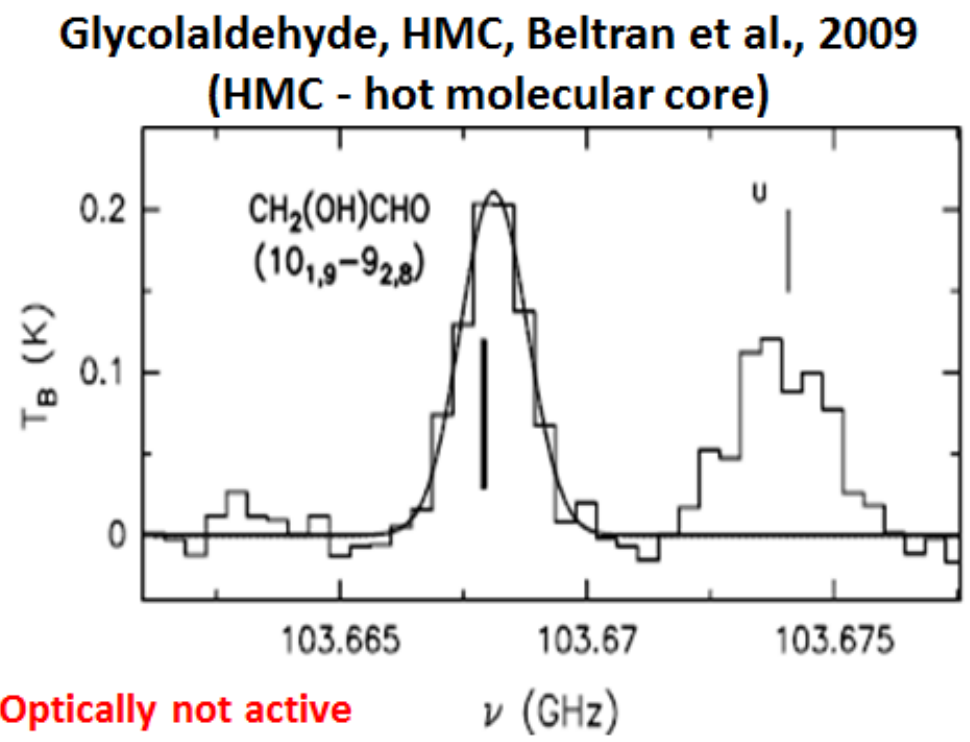

Figure 5.The simplest sugar, glycolaldehyde detected in hot molecular core (Beltran et al. 2009)

Glycine $\left(\mathrm{C}_{2} \mathrm{H}_{5} \mathrm{O}_{2} \mathrm{~N}, 206.468 \mathrm{MHz}\right)$ ?, Kuan et al. 2003

(optically not active)

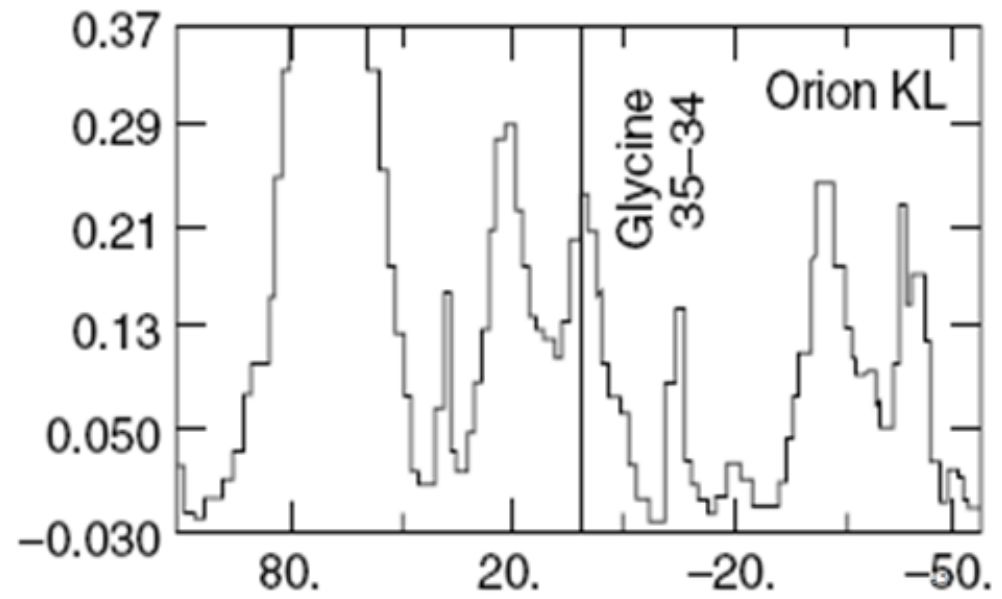

Figure 6.First interstellar glycine detected in Orion KL (Kuan et al. 2003). But its identification still is questioned.

One will adopt as a route of formation of glycolaldehyde surface reactions of $\mathrm{HCO}, \mathrm{H}_{2} \mathrm{CO}$, and $\mathrm{CH}_{3} \mathrm{OH}$, but one will note that these somewhat arbitrary choices do not imply that other routes are not important (Beltran et al. 2009). The chemical routs to the formation of glycolaldehyde then areas follows: $\mathrm{CO}+4(\mathrm{MH}) \Rightarrow \mathrm{MCH}_{3} \mathrm{OH} ; \mathrm{CO}+$ 
$\mathrm{MCH}_{3} \mathrm{OH} \Rightarrow \mathrm{MHCOOCH}_{3} ; \mathrm{H}_{2} \mathrm{CO}+\mathrm{MH} \Rightarrow \mathrm{MCH}_{3} \mathrm{O} ; \mathrm{MCH}_{3} \mathrm{O}+\mathrm{MHCO} \Rightarrow \mathrm{MHCOOCH}_{3} ; \mathrm{CO}$ $+2(\mathrm{MH}) \Rightarrow \mathrm{MH}_{2} \mathrm{CO} ; \mathrm{CO}+\mathrm{MH} \Rightarrow \mathrm{MHCO} ; \mathrm{MH}_{2} \mathrm{CO}+\mathrm{MHCO}+\mathrm{MH} \Rightarrow \mathrm{MCH}_{2} \mathrm{OHCHO}$, where " $\mathrm{M}$ " denotes species in the solid phase.The model already included hydrogenation on grains. The range of ages indicated by the best- fit models is consistent with a typical age for a HMC $\left(\sim 10^{5}-5 \cdot 10^{5} \mathrm{yr}\right)$.

Interestingly, glycine column densities observed in Orion $\mathrm{KL}$ are about of $\simeq 4 \cdot 10^{14} \mathrm{~cm}^{-2}$ and the hydrogen column density adopted is of $3 \cdot 10^{23} \mathrm{~cm}^{-2}$ so the fractional abundance of glycine with respect to molecular hydrogen is $1.3 \cdot 10^{-9}$ (Kuan et al. 2003). Glycine molecules are in warm, dense gas of hot-core where icy grain mantles have been evaporated. On the other hand, they may inevitably have been formed on grain surfaces and have been evaporated or synthesized in the gas phase by means of mutual reactions of evaporated molecules. Amino acids are very sensitive to UV radiation but they can survive due to very large absorption in HMC $\left(A_{V} \simeq 300\right.$ ) (Kuan et al. 2003).It may also depend on secondary radiation of UV photons (6-13 eV) caused by interaction of $\mathrm{CR}$ with $\mathrm{H}_{2}$ molecules. Thus, any energetic UV processing of grain mantles must have occurred in cold environment prior to hot-core formation. Recent experiments have shown that UV photolysis of interstellar ice analogs can produce some abundances of glycine and other amino acids (Kuan et al. 2003 and references therein).But up to now there is no quantitative theory explaining observations. Besides, there are still unanswered serious questions for production of amino acids in hot-core environment, in general, and the primary chemical production paths of glycine remain to be determined, especially concerning formation on the grain surface.

Amino acids were discovered in meteorites, with aliphatic and aromatic hydrocarbons and even with fullerens (Table 3) (Ehrenfreund et al. 2002). But what is much important these were optically active amino acids! Again, we will discuss such a circumstance later but now let highlight the point that very rich organic material may have been delivered to the primitive Earth by comets and meteorites.

As dust particles become part of a protoplanetary nebula, they are embedded in freshly originated cometary nuclei in the outer part of the forming planetary system, like in our own solar system 4.5 Gyr ago. Comets form in a colder part of the proto-planetary disk and are an agglomeration of various dust grains, or, to be more correct, the volatile components $\left(\mathrm{H}_{2} \mathrm{O}, \mathrm{CO}, \mathrm{CO}_{2}, \mathrm{NH}_{3}, \mathrm{CH}_{4}, \mathrm{CH}_{3} \mathrm{OH}\right.$, etc. ) contribute $\approx 40 \%$ by mass plus roughly equal amounts of the refractory components in the form of silicates and complex organic material dominated by carbon (Greenberg \& Li 1999). Therefore, a great deal of organic chemistry in dust grains has already taken place under conditions of the ISM and the proto-planetary disk before the formation of the cometary nucleus. It is generally accepted now that newly originated comets 
were scattered by giant planets and caused a "heavy bombardment" of the inner planets including Earth between 4.5 and 3.8 Gyr ago (Delsemme 1997). The question, to what extent cometary matter is of interstellar or solar nebula origin, is still open, but what is now quite obvious is that comets (and/or micron-sized particles) have brought to the Earth a significant amount of volatile compounds.

Table 3. Carbon containing species in meteorites. Pay attention to aminoacids (aa) with enanthiomeric excess (ee).Adopted fromEhrenfreund et al. (2002)

\section{Carbon containing species in meteorites - aa with ee !}

Compound class

Amino acids/CM meteorites

Amino acids/CI meteorites

Aliphatic hydrocarbons

Aromatic hydrocarbons

Fullerenes

Carboxylic acids

Hydrocarboxylic acids

Dicarboxylic acids and Hydroxydicarboxylic acids

Purines and Pyrimidines

Basic N-heterocycles

Amines

Amides linear

Amides cyclic

Alcohols

Aldehydes and Ketones

Sulphonic acids

Phosphonic acids
Concentration $(\mathrm{ppm})$

Optically active

$17-60$

$\sim 5^{\mathrm{a}}$

$>35$

$3319^{\mathrm{b}}$

$>100^{\mathrm{c}}$

$>300$

15

14

1.3

7

8

$>70$

$>2^{\mathrm{d}}$

11

27

68

2

As the pre-solar nebula collapsed, solid particles settled to the midplane. They may have undergone various processing of their icy mantles as they fell: nevertheless a generally accepted point of view is that much of the interstellar material is incorporated unaltered into comets. The planetesimals (cometesimals) grew by collisional coagulation until they were big enough to decouple from the turbulence between the dust layer and the gas. Also because collisions were caused by differential radial velocities induced by gas drag, a single comet nucleus may have incorporated cometesimals from different heliocentric distances. At the same time there is much evidence that planetesimals at Earth's heliocentric distance would have accreted from dust particles too hot to have retained volatile elements. Thus on the one hand, the proto-Earth was completely outgassed up to its final formation, and, 
on the other hand, examination of the lunar cratering record suggests that the terrestrial water and other volatiles could have a cometary origin. The case is that during the process of formation, vast numbers of comet-like objects were scattered by giant planets into interstellar space and the inner Solar System, resulting as is mentioned in the so-called "heavy bombardment" period of the Earth 4-4.5 Gyr ago. It is generally accepted now that outgassing of Earth's mantle was the major source of water and the early atmosphere (Campbell et al. 2012) while some authors in recent works have argued that the ocean's water, the primary atmosphere's components and carbon-bearing volatiles were delivered into the Earth by comets and/or dust particles sized within the range of 10-100 micron (Maurette2006 ).

$n$-Alkanes and isoprenoid hydrocarbons are found in sedimentary rocks dating back 3.2 Gyr ago and are beleived to constitute chemical evidence for the earliest biosynthesis (Brooks and Shaw 1973). What are these hydrocarbons with a very stable molecular architecture, a «chemical fossil» whose carbon sceleton suggests an unambiguous link with a known natural bioproduct, or potential building block for future primitive cells - this is a question outside the scope of this work. But what is now quite obvious is that comets and micron-sized dust particles have brought to the Earth a significant amount of complex organics. What concerns cometary collisosns Blank and Miller (1998) and, indepedently, Svetsov (2002) have shown that under conditions of low angle impact $\left(5-10^{\circ}\right)$ a few percent of the comet's organic matter might have survived due to jetting in opposite direction with the impact velocity thus providing soft-landing of cometary organics. Under reduced atmosphere conditions (Lewis, Prinn 2004) this material was readily preserved, buried and transformed into petroleum (Gold 1999) which, of course, does not refute a theory of biogenesis of oil, after origin of Life at later times, becauselater bioorganics may also be added coming with sedimentary rocks. A comet $10 \mathrm{~km}$ in diameter and with $x$ fraction of refractory material like mixture of bitumens, heavy aliphatic and aromatic hydrocarbons, may deliver about $10 \cdot x$ billion tons of such a material to a limited rocky Earth surface(10-100 km²) with a thikness of a uniform layer of 0.01-1 $\mathrm{km}$. It should be recalled here that according to data about lunar crutering during the heavy bombardment period over 100 million comets impacted the Earth 4-4.5 Gyr ago (Delsemme 1997) and it is straightforward to estimate that about 1 percent of impactors would have had a low-angle impact (less than 5-10 ${ }^{\circ}$ ) (Pierazzo, Melosh 2000).In this case one simply gets a ready-made giant oilfield (of inorganic origin).By the way, one needs only no more than 100 «soft-landing» events (one per million) to get amount of petroleum which is comparable to the modern value of world petroleum. Of course, such oilfields have nothing common with origin of modern petroleum because of following tectonic processes. 
We have also discussed a possible link between the extraterrestrial heavy hydrocarbons and terrestrial prebiotic petroleum and have shown that inevitable consequence of the existing scenario of the Earth origin is the outer delivery and accumulation of complex hydrocarbons in countable amounts prior to the origin of Life (Gold 1999; Kagramanov, Yeghikyan 2000). Sothere is no doubt that some link with the origin of Life should be present.It is worthy to note that the role of polyisoprenoid components in the transition from chemical evolution to biological evolution may have been especially significant (McCarthy, Calvin 1967).

\section{Recycling of carbon-containing material in the Galaxy}

Carbon-containing dust is originated mainly in the SN expanding shells and cold outflows of $A G B$ stars and one limit a discussion with $A G B$ dust because their contribution is comparable and even larger for graphite when speaking about Solar System (Zhukowska 2008). To form planetary nebulae (PN) AGB stars need to have intense outflows at the transition phase to PN (Kwok, 2000). Winds due to thermal pulses of AGB stars with mass loss rates of $\sim 10^{-5}-10^{-4} \mathrm{M}_{\odot} / \mathrm{yr}$ and velocities of 10$20 \mathrm{~km} / \mathrm{s}$ form the material of future PNe. The characteristic time scales of these processes are such that the increased temperature of the star at the end of the AGB stage causes photoionization of the ejected shell and transformation to the PN. Transition to the final phase takes place in a relatively short period of a few 100 years. At the same time, the slow and intensive outflow of cold stellar matter is transformed into a hot, fast but less intense stellar wind with the rate of $10^{-9}-$ $10^{-7} M_{\odot} /$ yr and a speed of $\sim V_{*} \sim 1400-5000 \mathrm{~km} / \mathrm{s}$ (Kwok, 2000). The further dynamical evolution of the $\mathrm{PN}$ is determined by the interaction of the new rapid outflow with the previous slow one, causing the expansion of the PN at a rate of 20$40 \mathrm{~km} / \mathrm{s}$ and larger.

Interestingly, a large number of molecules is observed in PN (Kwok 2000; Yeghikyan 2017 and references therein). As usual, the existence of the molecules is connected to the region behind the photoionization and photodissociation fronts separating the inner fully ionized part from the outer neutral and molecular envelopes. The presence of such envelopes follows from observational and theoretical data about PN and AGB stars. Indeed, the observed mass of the $\mathrm{H}^{+}$zone is of order of several $0.1 M_{\odot}$ and does not exceed $0.5 M_{\odot}$, while stellar evolution on the AGB star demands the total (the sum of ionized, neutral and molecular parts) PN mass to be of the order of one or more solar masses, up to 3-4 $M_{\odot}$. Clearly molecules are present in the PN because of self-shielding by sufficient amounts of molecular gas in the form of the simplest and most common species $\left(\mathrm{H}_{2}, \mathrm{CO}\right.$ and $\left.\mathrm{OH}\right)$, more complex species $\left(\mathrm{H}_{2} \mathrm{O}, \mathrm{SiO}, \mathrm{HCN}, \mathrm{HNC}, \mathrm{HCO}^{+}\right)$, and even polycyclic aromatic 
hydrocarbons (PAHs) and fullerenes containing several tens or more atoms. Molecules of $\mathrm{H}_{2} \mathrm{O}$ are observed both in the gas phase (water "fountain" and related masers in young PN) and in the solid phase (emission from crystal water ice).

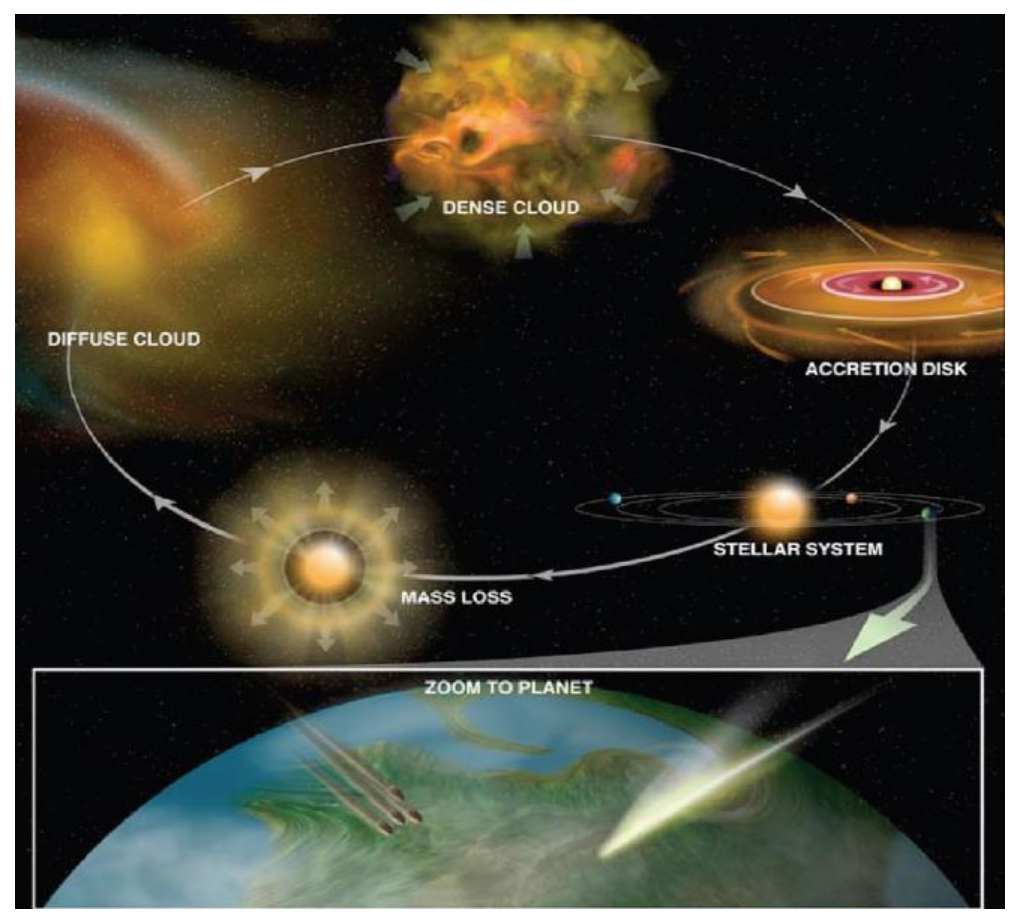

Figure 7. How organics is recycling in the Galaxy (Kwok 2011)

It should be also added, that molecules responsible for the characteristic features of the observed spectra, may be partly associated with nebular condensations. As is known, they are observed in PN as small (milli)globules with sizes of $\sim 10^{15}-10^{16} \mathrm{cmand}$ concentrations of $\sim 10^{5}-10^{6} \mathrm{~cm}^{-3}$ : for example, in the nearest NGC 7293 there are about 3500 of such objects (Kwok, 2000). Probably, they formed in the AGB-wind phase, as a result of the Parker magnetohydrodynamic instability, and should be differentiated from other types of (gas-dynamic) instabilities developing at a relatively later stages of the PN evolution. In general, such irregularities are important observable characteristics of all stellar winds, and PN are the good example of their manifestation. One can describe the condensations as cold (about $10 \mathrm{~K}$ ), dense $\left(\sim 10^{6} \mathrm{~cm}^{-3}\right)$ and molecular, with masses of the order of $10^{-6} M_{\odot}$ each, surviving over the full PN dynamical lifetime of $\sim 10^{4}$ years. This prediction was confirmed by direct observations of NGC 7293 with (milli)globules. On the other hand, the characteristic times of the mentioned instabilities in PN, possibly leading to the formation of clumps, is clearly less than time of the PN phase. Also $\mathrm{H}_{2}$ molecules begin to dominate quickly via formation from atomic hydrogen on the surface of dust grains, for a time of about $1.5 \cdot 10^{9} / n$ years (Dopita, Sutherland, 
2001), then forming a gas component, effectively shielding the inner regions of the condensation from the hard UV radiation (it should be recalled that photodissociation of $\mathrm{H}_{2}$ is realized through the dominant reaction channel with the interaction cross-section of $\sim 10^{-14} \mathrm{~cm}^{2}$ (Dopita, Sutherland, 2001). Under such conditions, saturated compounds like water, ammonia and methane are also formed and condensed on the grain surfaces with the characteristic timescale of 3 . $10^{9} /$ nyears. In other words, in condensations $\left(n \sim 10^{6} \mathrm{~cm}^{-3}\right)$ icy mantles of dust particles must form in less than 3 thousand years; e.g., the most abundant solid water with frozen other volatiles ( $\mathrm{CO}, \mathrm{NH}_{3}$ etc.) form the ice mantles with thicknesses up to a few $0.1 \mu$ that are about one order of magnitude larger than the initial size of the silicate and/or graphite dust cores of $\sim 0.01 \mu$ coming from the AGB phase cold wind. This should be true also for mentioned conditions of young PN with the following reservation: icy particles may be present there coming from the cold AGB outflows and surviving as long as they are shielded from radiation. In any case, because the time of the $\mathrm{H}_{2}$ formation is also relatively small (about 1.5 thousand years under young PN and milliglobules conditions as compared with the dynamical time of $10^{4}$ years) one may choose in a first approximation, a stationary model to describe the young PN and (milli)globules in terms of the balance between the formation and destruction of the most important molecules (and ices). Thus, icy mantles on dust particles (water, ammonia, methane, methanol, carbon monoxide, etc.) are possible in the young PN and even in the (milli)globules regardless of the condensations origin. Such icy particles are protected from exposure to extreme UV radiation and from vaporization during the lifetime of the (young) PN and that of the (milli)globules. At the same time, as is known, these ices should be irradiated by UV with wavelengths larger than $912 \AA$. According to experimental data, the irradiation of mixture of ices like $\mathrm{H}_{2} \mathrm{O}: \mathrm{CH}_{3} \mathrm{OH}: \mathrm{NH}_{3}$ : $\mathrm{CO}$ by the UV radiation with a photon energy of about $10 \mathrm{eV}$ (vacuum UV, below VUV), causes the formation of highly complex compounds containing, for example up to 22 carbon atoms. It is also possible to form amino acids, $\mathrm{PAH}$, etc. The threshold dose of the accumulated energy to initiate radiationchemical transformation is $25 \mathrm{eV} /$ molecule.

It is interesting to note that, in recent years, infrared observations, as already noted, registered PAH, and even fullerenes $\mathrm{C}_{60}$ and $\mathrm{C}_{70}$ in the spectra of several PN, including 11 out of 338 observed by Spitzer(Fig. 8). These authors interpret their observations as follows: the most likely places of formation of such compounds are the outflows of cold carbon stars in the AGB phase transition to the PN, but little details are known. In particular, it is unclear whether they are present initially in $A G B$ winds, but not observed, due to the lack of appropriate sources of excitation, or they form during the process of transition to a PN phase. There is a point of view that 
fullerenes are formed by the UV destruction of hydrogenated amorphous carbon (HAC) and/or the dehydrogenation of large PAH molecules in the early PN stages, when there is the intense UV irradiation. The quantitative description of this hypothesis is not known but many experimental data are available. Nothing is known also about quantitative characteristics of the effectiveness of joint UV and corpuscular irradiation of dust inside the condensations and behind the PN photodissociation front.

In a recent article Kwok (2011) discussed the possibility of recycling of organic matter in the Galaxy, just in the context of origin of the stable complex species during the transition phase from the $A G B$ winds to the $P N$, with the possible formation of carbon-containing compounds. One should stress, however, that a no less important factor in the problem of the primary origin of complex compounds is the survivability of more abundant, but less stable ices (e.g. water etc.) and/or their mixtures under PN conditions.

\section{Large molecules (nanoparticles) - PAHs - in the cold stellar outflows and $\mathrm{C} 60$ in the ISM}

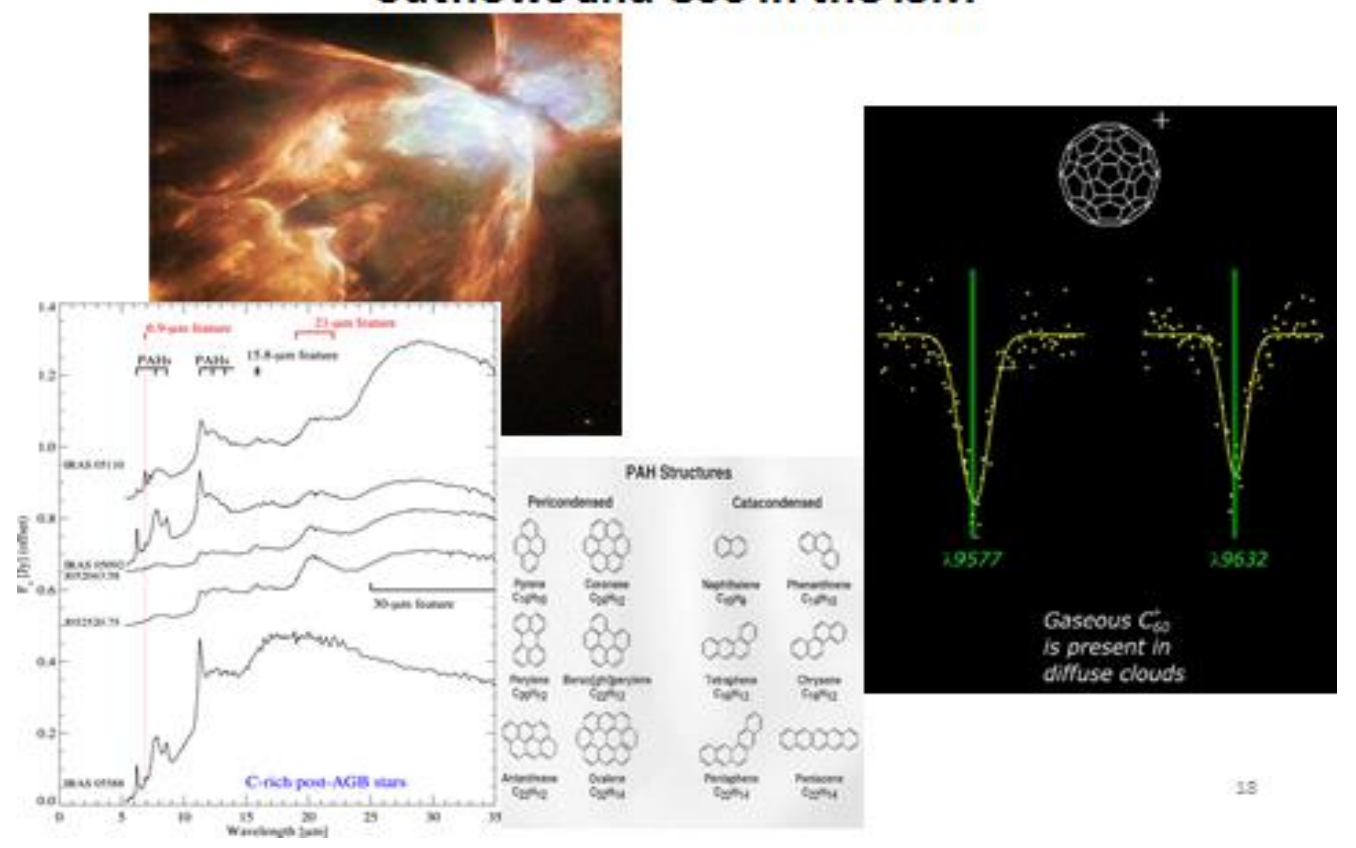

Figure 8. $\mathrm{PAH}$ in the various interstellar environment

Organics recycling in the Galaxy (Kwok 2011) mean, amongst others, that large molecules (nanoparticles like fullerens and polycyclic aromatic hydrocarbons, PAHs) are originated in the cold stellar outflows and scattered in the ISM and then enter into molecular clouds. Molecules can also survive inside condensations in planetary 
nebulae (Fig. 9) evidencing the recycling of organics in the Galaxy, and showing, by the way, PAH and fullerens $\mathrm{C} 60$ andC70!

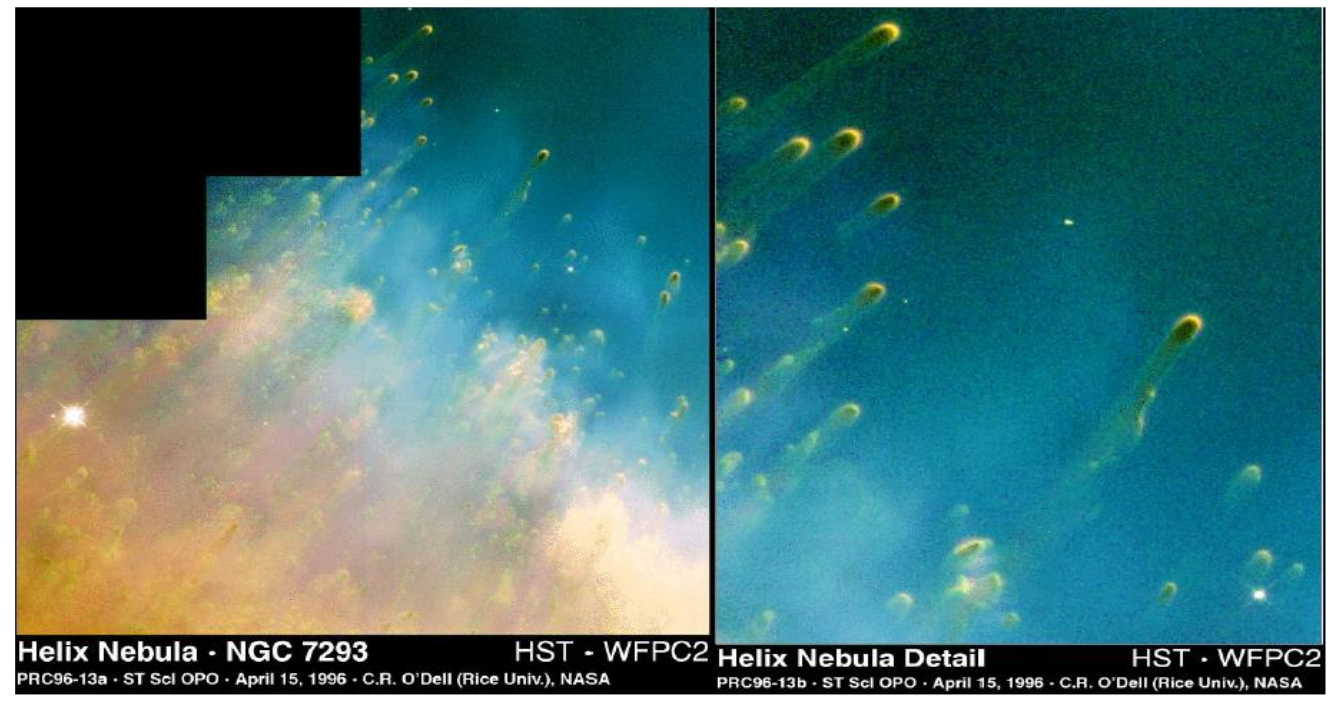

Figure 9. Molecules survive in condensations in the late stage of planetary nebulae

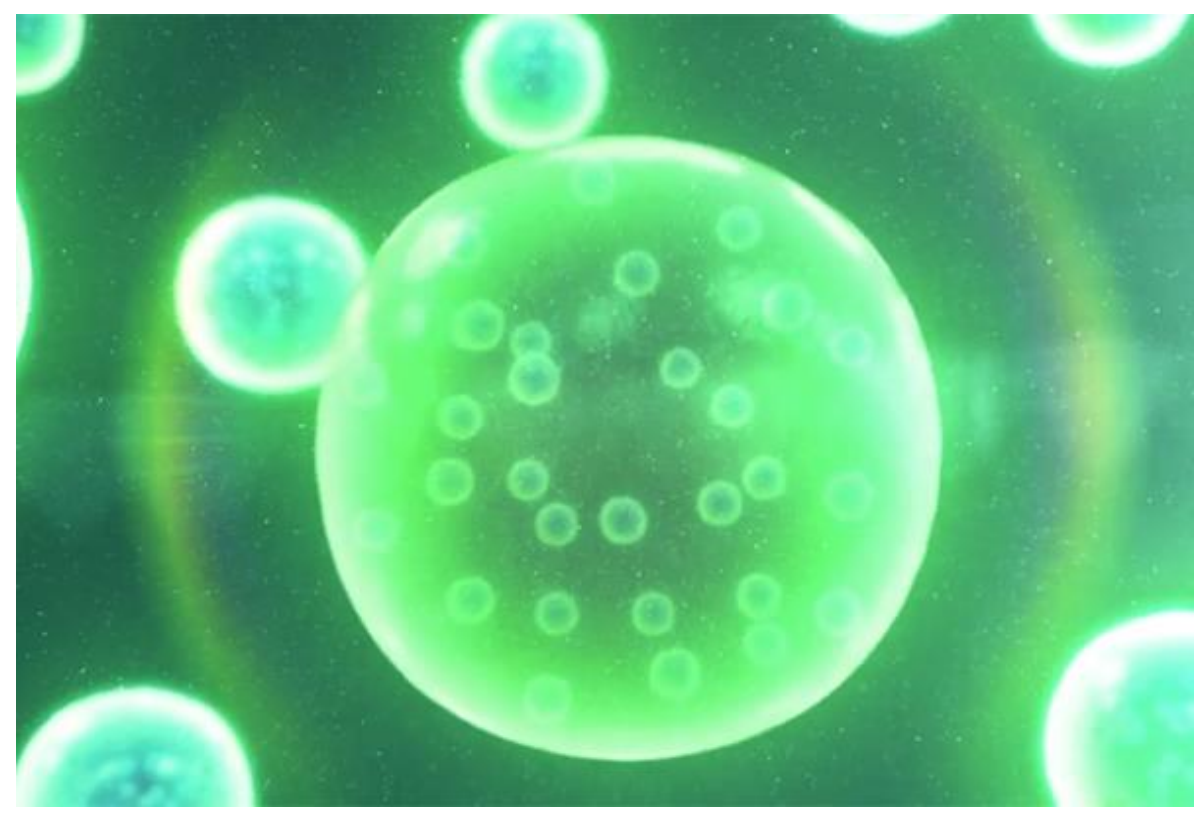

Figure 10.Chemically active droplets as a model for protocells on the early Earth - Zwicker et al., 2017; Haldane, 1955;Oparin, 1924.Deamer et al. (2002) have shown that the "membrane first" hypothesisneeds the lipid bilayer(lipids, pospholipids, et cetera).

\section{Step 4 - "separation" first.}

Chemically active droplets as a model for protocells on the early Earth are widely discussed and mean in general, "membrane first" hypothesis whichneeds the lipid bilayer (lipids, pospholipids, et cetera)(Fig. 10) (Meierhenrich 2008; Ehrenfreund et al. 
2002).McCarthy and Calvin (1967) were first mentioning about polyisoprenoid compounds as important ingredients to make such bilayers in Yeghikyan and coworkers (2001, 2004, 2013a) and Yeghikyan (2008, 2009, 2011, 2013b, 2015, 2017) discussed some details concerning creation in space and accumulation of such species on the Earth. Thus "membranes first "hypothesis (in aqueous environment) also is connected with polyisoprenoid hydrocarbons: it was suggested by McCarthy and Calvin (1967) and hightlighted itsrole. In fact McCarthy and Calvin(1967) have proposed an idea about «polyisoprenoid compoundsfirst!» (see also Keheyan et al. 2004; Yeghikyan, 2013b, 2015). One should conclude that isoprene $-\left(\mathrm{C}_{5} \mathrm{H}_{8}\right)-2-$ methyl $-1,3$ - butadiene : $\mathrm{CH}_{2}=\mathrm{C}\left(\mathrm{CH}_{3}\right)-\mathrm{CH}=\mathrm{CH}_{2}$ and its derivatives play an important role as membrane making subunits.

\section{Where do Membrane making molecules come from ?}

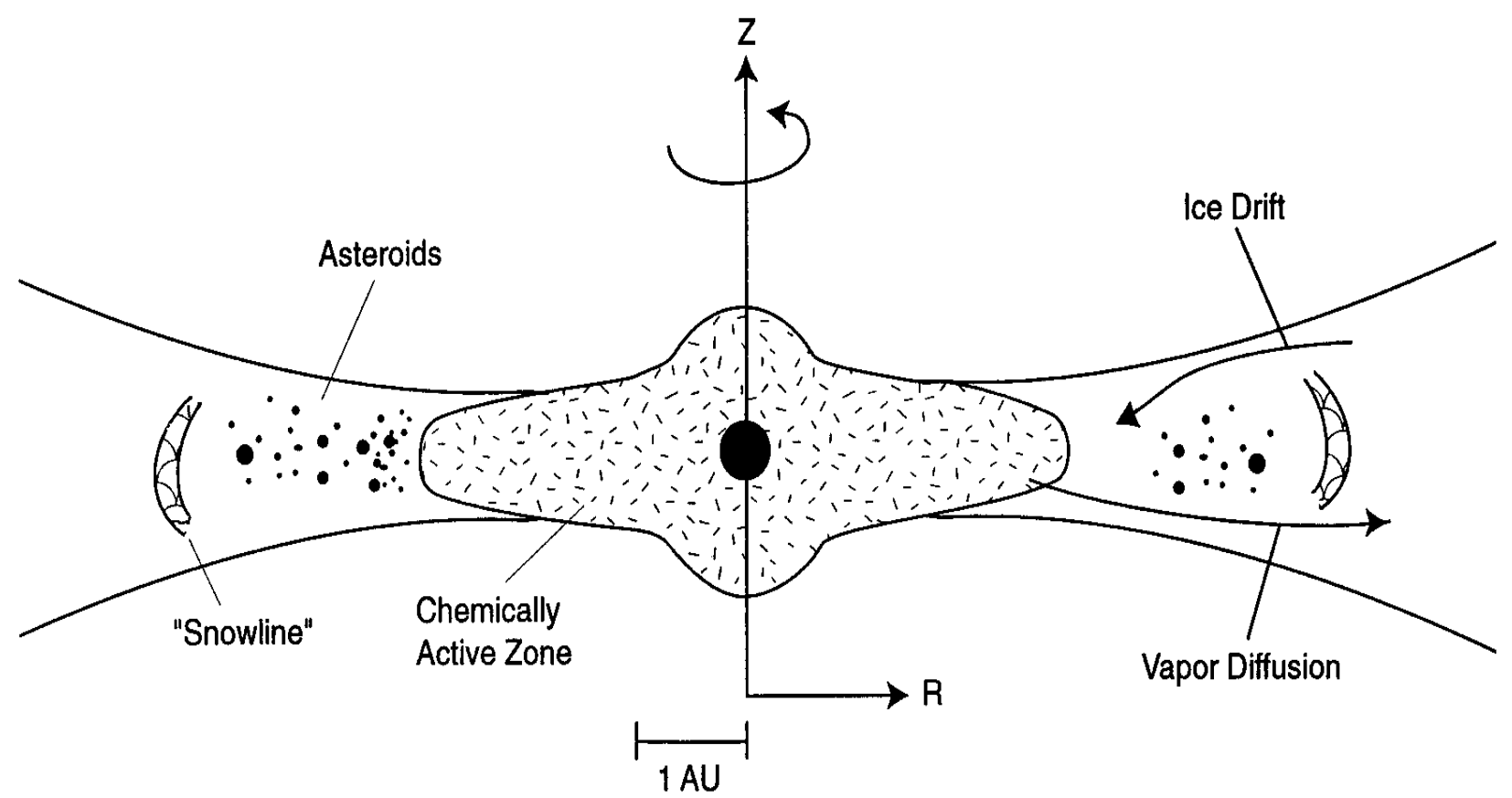

Figure 11. Physical-chemical stratification in the protosolar disk (Delsemme 1997)

The surface of the newborn Earth was too hot ( $800 \mathrm{~K})$. Atmosphere was neutral $\left(\mathrm{CO}_{2}+\mathrm{N}_{2}\right)$ so no direct polymerization/polycondensation was possible and also no Fischer-Tropsch Synthesis above $\mathrm{C}_{15} \mathrm{H}_{\mathrm{m}}$ might be happened (Pearce and Pudritz 2015, and references therein). There is widely accepted now that needful organics was delivered on the Earth by comets and large dust particles (Ehrenfreunde et al. 2002; Keheyan et al. 2004; Yeghikyan 2013b and references therein). Physicalchemical stratification in the protosolar disk revealed by many models has shown that such comets and dust were originated beyond the so called snow and tar lines 
(Fig. 11)which permits to suggest a following observational test for polyisoprenoids that is the search of corresponding lines of solid polyisoprenoid hydrocarbons in protostellar disks, that is vibrational lines of dienic molecules in the range of 3.23$13.7 \mu \mathrm{m}$ (Sverdlov et al. 1979).

I conclude with CR and VUV induced polycondensation of solid $\mathrm{CH}_{4}$ followed with aliphatic heavy hydrocarbons up to $\mathrm{C}_{29} \mathrm{H}_{60}$ should be accounted as a key process of complexization. A probablearomatization due to VUV resulted with small $\mathrm{PAH}$, e.g. $\mathrm{C}_{24} \mathrm{H}_{12}$ is also an important way to get species widely observed in space. Circumstellar disks show many predecessors of PAH with aliphatic bonds (Yeghikyan 2013b and references therein).

\section{Basics of astrobiological scenarios concerning the origin of life on the Earth.}

A short summary of generally accepted scenarios is followed (Ehrenfreunde et al. 2002; Keheyan et al. 2004; Meierhenrich 2008; Yeghikyan 2013b, and references therein).

Water for oceans was delivered by comets and dustaround 4.5-3.8 Gyr ago $(\mathrm{D} / \mathrm{H}$ is well agreed). The terrestrial primordial atmosphere which was also created by such a way was neutral $\left(\mathrm{CO}_{2}+\mathrm{N}_{2}\right)$. Organics delivered on the Earth by comets and interplanetary dust particles must already have contained chiral species because molecular symmetry could not be broken under terrestrial conditions (see below). Comets impacting the Earth with grazing trajectories (with $\alpha \leq 5^{0}, 2-3 \%$ of all impacts) created first biochemical reactors or "little warm ponds" (Darwin).Life (on Earth) has originated $3.8 \mathrm{Gyr}$ ago immediately after cessation of the "heavy bombardment" period.

\section{Step 5 - chiralization}

Homochirality is a key distinguisher of Life and chiral molecules should be important "precursor" to first living organisms (Meierhenrich 2008). Chiral molecules older than the Earth itself have been spotted in meteors and comets. The most effective mechanism to get enantiomeric enhancement is enantiomerically selective photochemistry induced by circularly polarized light of $6-13.6 \mathrm{eV}$ (Meierhenrich 2008).

Terrestrial organisms use one enantiomer only. Protein synthesis, gene transcription and metabolism essentially depend on homochirality (Fig. 12, 13). A question is raised are Miller-type experiments $\left(\mathrm{CH}_{4}, \mathrm{NH}_{3}, \mathrm{H}_{2} \mathrm{O}, \mathrm{H}_{2}\right.$ +energy source with resulting complex species) adequate as direct analogs for Life origin ? (Fig. 14). The answer is No! The case is that terrestrial primitive atmosphere was not reduced (no 
$\mathrm{H}_{2}, \mathrm{CH}_{4}$ - no polymerization/condensation) and moreover, produced aminoacids were racemic.So one should look for extraterrestrial conditions to get chiral species !

Terrestrial organisms use one enantiomer only

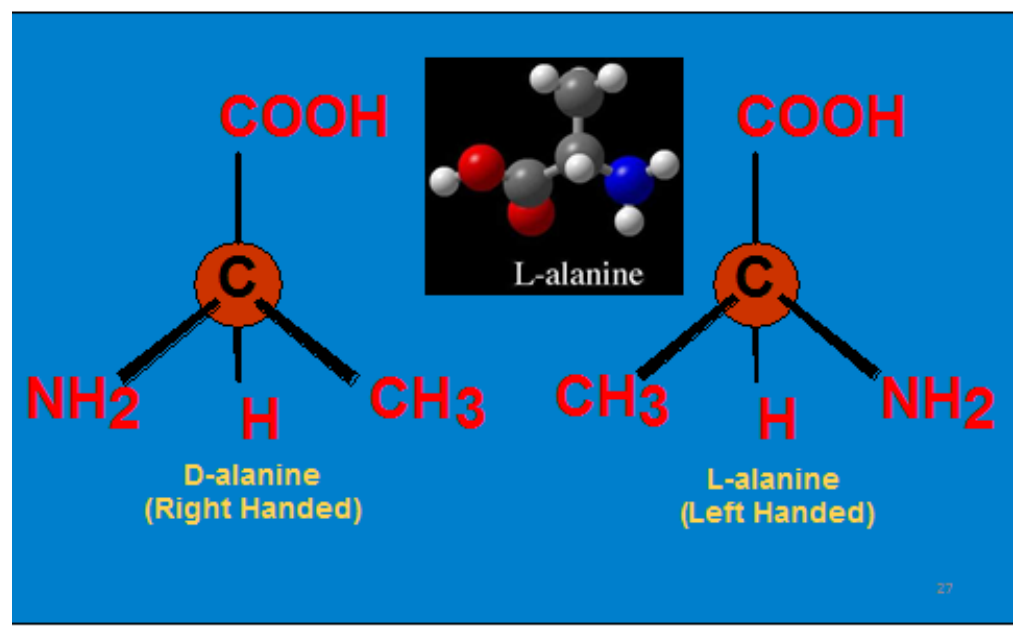

Fig. 12.Our Proteins consist of left-handed amino acids.

\section{Protein synthesis, gene transcription, metabolism essentially depend on homochirality}
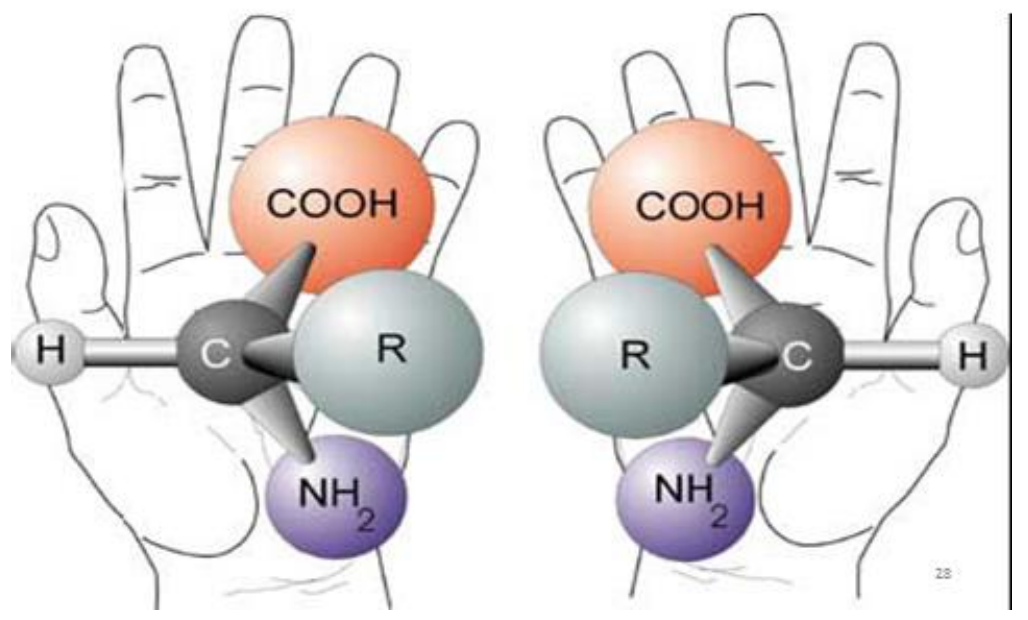

Figure 13. The basic biochemical transformation essentially depend on homochirality.

Recently, McGuire et al. (2016) had discovered the first complex organic, potentially chiral molecule in the ISM (Fig. 15, 16). The molecule, propylene oxide $\left(\mathrm{CH}_{3} \mathrm{CHOCH}_{2}\right)$, was found near the center of our Galaxy in a star-forming cloud Sagittarius B2 (Sgr B2).The current data, however, do not distinguish between the left- and right-handed versions of the molecule. In additional to the same chemical composition, chiral molecules have the same melting, boiling, and freezing points, and the same spectra. The researchers believe it may eventually be possible to 
determine if there is an excess of one handedness of propylene oxide over the other by examining how polarized light interacts with the molecules in space.

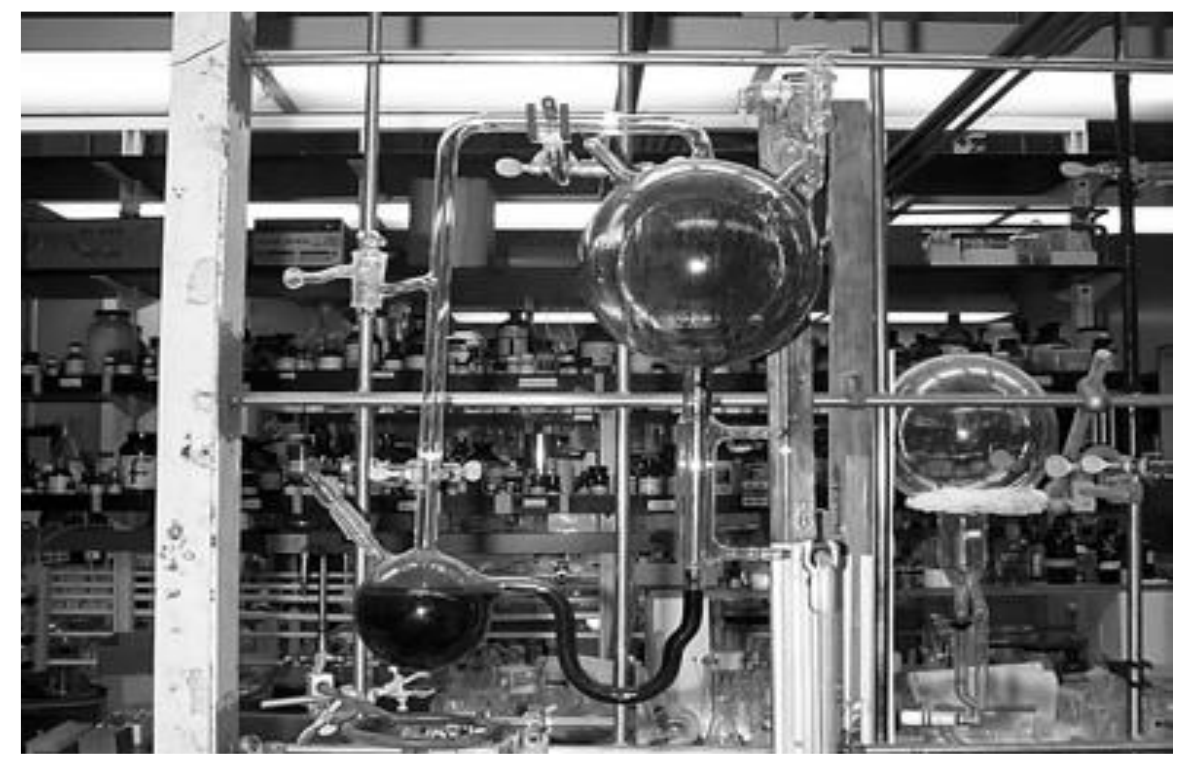

Figure 14. Miller-Uri experiments $\left(\mathrm{CH}_{4}, \mathrm{NH}_{3}, \mathrm{H}_{2} \mathrm{O}, \mathrm{H}_{2}\right.$ +Energy source) resulting various complex species but only racemic!

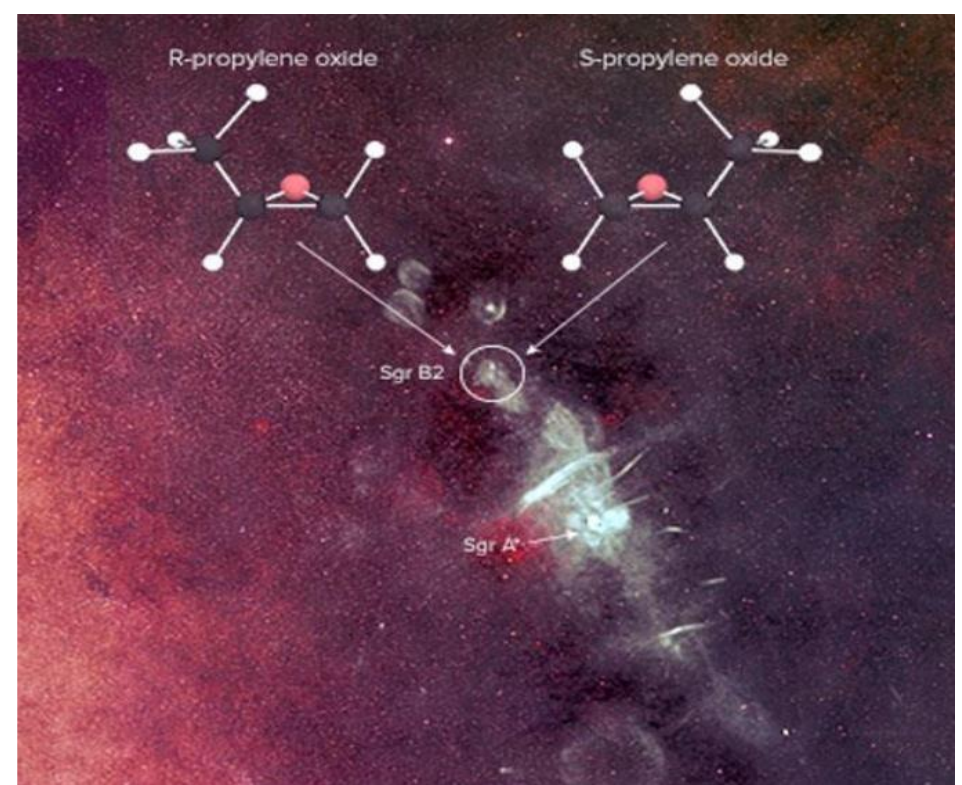

Figure 15. Potentially chiral species (propylene oxide) detected in space (McGuire et al. 2016)

Researchers note that "the next step is to detect an excess of one enantiomer over the other" (McGuire et al. 2016).

Theoretical models show that propylene oxide is originated on the surface of dust grains and then has been removed due to increased temperature of the environment. So again one comes to the conclusion that only surface reactions may arrange the complexization needed! 
Now and again - the best way to getsuch complex molecules, and what is very important, in chiral form, isvia grain surface reactions under appropriate irradiation by asymmetric agents (Fig. 17).Astrobiologists now are urgently looking for such asymmetric agents for photoreactions. One may list corresponding Advantage factors with decreasing effectiveness - Circularly polarized VUV radiation, Polarized electrons, Magnetic fields, Rotation, Parity violation in weak interactions, Surfaces of crystalls (quartz) and clays (caolinit) (Meierhenrich 2008).Problems of seeding chirality and its amplification are also challenging.
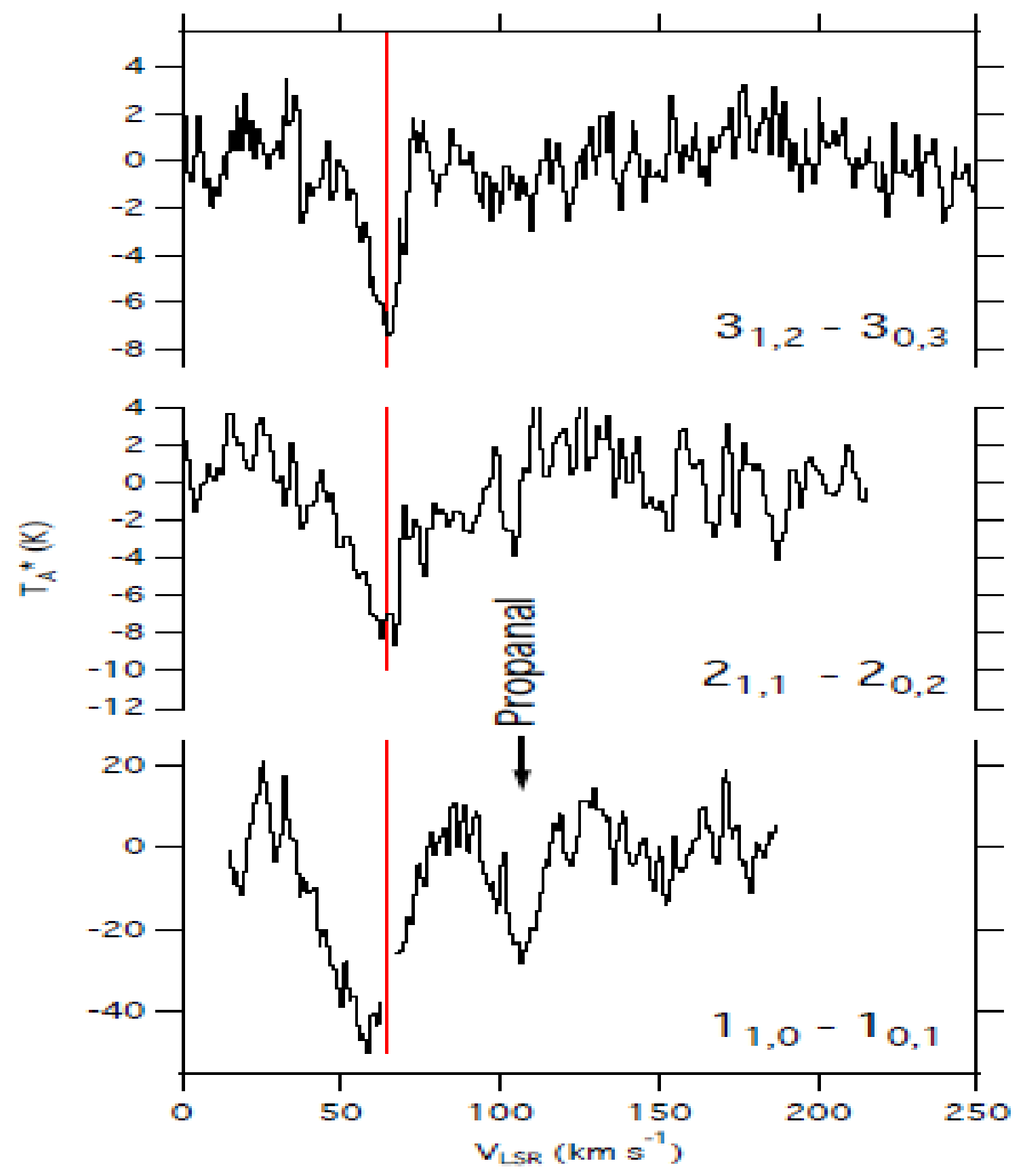

Figure 16.McGuire et al. (2016) confidently identified potentially chiral propylene oxide at 2.5, 2.3 and $2.1 \mathrm{~cm}$. 


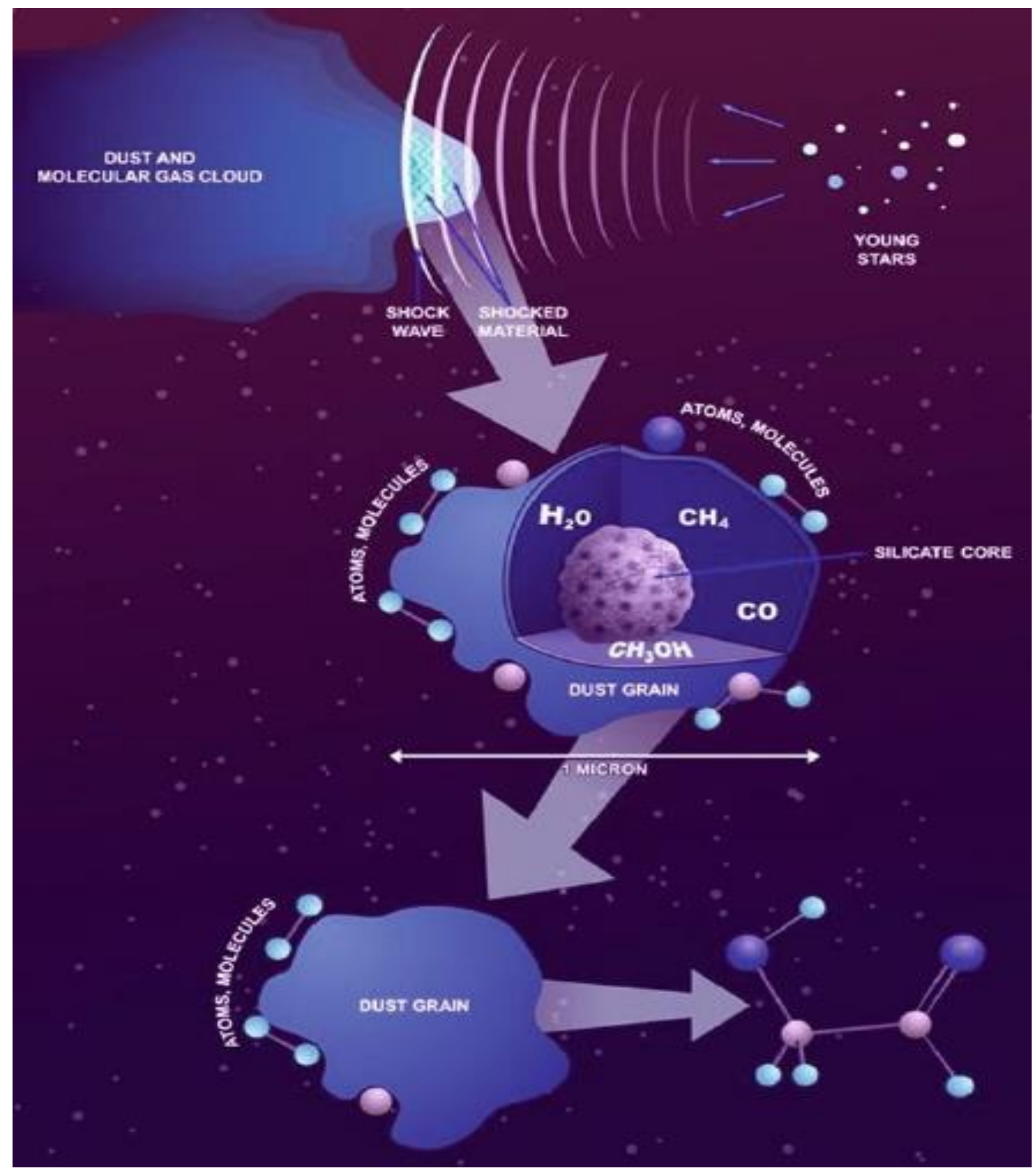

Figure 17. Only surface reactions can arrange the demanded complexity (adopted from Yamamoto 2017).

So a very important question should be Where do Prebiotic molecules come from? - really from a natal cloud, or may be from a disk, or from other exoplanet (Fig. 18)? 


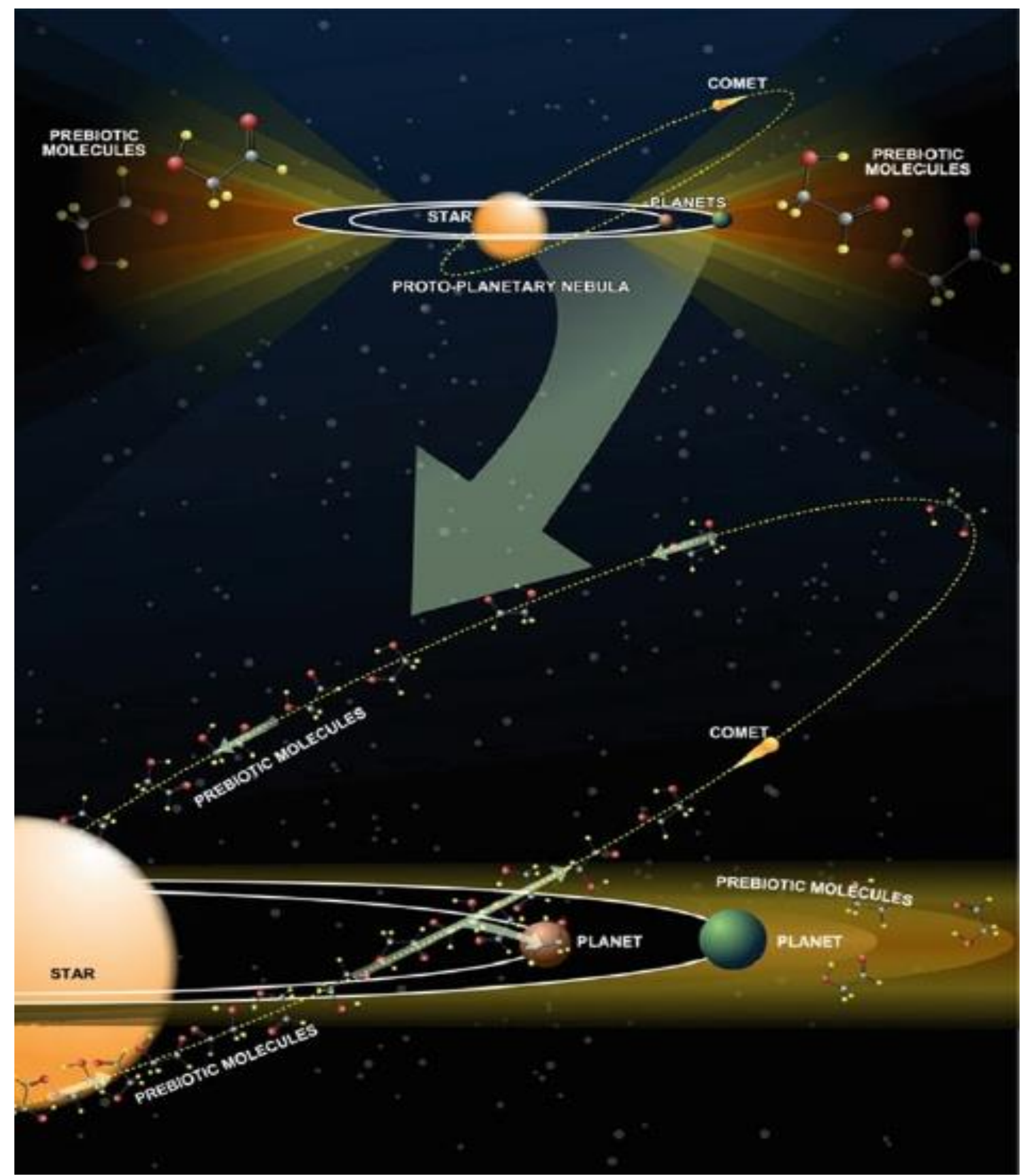

Figure 18. Where do Prebiotic molecules come from ? - From a natal cloud, or may be from a disk, or from other exoplanet ?(Adopted from Yamamoto 2017).

Astrophysicists need more precise observational and theoretical data to get first answers to such complicated questions.

\section{Bio-signatures on exoplanets}

What one can say about possible bio-signatures in exoplanets from astrophysical point of view? Life as we know it is chiral, e.g. cyanobacteria, chlorophylls etc. This is may be used to detect possible bio-signatures if vegetation of plant is present. Using 
reflection spectro-polarimetry with circular polarization one may try to find some corresponding bands at 680,620,590, 560 and $430 \mathrm{~nm}$ (Sparks et al. 2009). Also life needs as a rule $\mathrm{H}_{2} \mathrm{O}$ and $\mathrm{O}_{2}$ and results $\mathrm{CH}_{4}$ : important spectral bands are in 600-700 $\mathrm{nm}$ and $3.4-18 \mu$ (Sverdlov et al. 1979). Discussion about real possibility to detect such details in the exoplanets reflecting light is out of scope of this paper.

An interesting method to distinguish bio-signatures on exoplanets was proposed by Hegdeand \& Kaltenegger (2013) comparing color indexes B-I versus B-V.

Table 4.Extremophiles on exoplanets and their properties (Hegde, Kaltenegger 2013).

\begin{tabular}{|c|c|c|c|c|c|}
\hline Environmental & Class & Defining Growth & Environment/ Source & Remotely Detectable & Example \\
\hline Parameter & & Condition & & Observable & Organisms \\
\hline High Temperature & Hyperthermophile & $>80^{\circ} \mathrm{C}$ & Submarine Hydrothermal Vents & Water & $\begin{array}{l}\text { Pyrolobus fumarï, Strain } 121 \\
\text { Simechor }\end{array}$ \\
\hline Low Temperature & $\begin{array}{l}\text { Thermophile } \\
\text { Psychrophile }\end{array}$ & $\begin{array}{l}60-80^{\circ} \mathrm{C} \\
<155^{\circ} \mathrm{C}\end{array}$ & $\begin{array}{l}\text { Hot Spring } \\
\text { Ice, Snow }\end{array}$ & Ice, Snow & $\begin{array}{l}\text { synechoococclus livdis, Jutjoloous sp. } \\
\text { Psychrobacter, Methanogenium spp. }\end{array}$ \\
\hline High pH & Alkaliphile & $\mathrm{ph}>9$ & Soda Lakes & Salt & $\begin{array}{l}\text { Bacillus frrmus OF4, } \\
\text { Heloangerhbium alcalinhilum }\end{array}$ \\
\hline Low pH & Acidophile & $\begin{array}{l}\text { ph }<5 \text { (typically } \\
\text { much less) }\end{array}$ & $\begin{array}{l}\text { Acid Mine Drainage, } \\
\text { Volcanic Springs }\end{array}$ & Acid Mine Drainage & $\begin{array}{l}\text { Picrophilus oshimaeltoridus, } \\
\text { Stygiolobus azoricus }\end{array}$ \\
\hline High Pressure & Piezophile & High pressure & $\begin{array}{l}\text { Deep Ocean } \\
\text { eg. Mariana Trench }\end{array}$ & Water & $\begin{array}{l}\text { M.kandleri, Pyrococcus sp., } \\
\text { Colwellia sp. }\end{array}$ \\
\hline Radiation & - & $\begin{array}{l}\text { Tolerates high levels } \\
\text { of radiation }\end{array}$ & $\begin{array}{l}\text { Sunlight } \\
\text { eg. High UV radiation }\end{array}$ & Sand, Rocks & $\begin{array}{l}\text { Deinococcus radiodurans, } \\
\text { Thermococcus gammatolerans }\end{array}$ \\
\hline Salinity & Halophile & $2.5 \mathrm{M} \mathrm{NaCl}$ & Salt Lakes, Salt Mines & Salt & $\begin{array}{l}\text { Halobacteriaceae, Dunaliella salina, } \\
\text { Halanaerobacter sp. }\end{array}$ \\
\hline Desiccation & Xerophile & Anhydrobiotic & Desert, Rock surfaces & Sand, Rocks & $\begin{array}{l}\text { Artemia salina, Deinococcus sp., } \\
\text { Lichens, Methanosarcina barkeri }\end{array}$ \\
\hline Rock-dwelling & Endolith & Resident in rock & $\begin{array}{l}\text { Upper subsurface to deep } \\
\text { subterranean }\end{array}$ & Rocks & $\begin{array}{l}\text { Lichens, Cyanobacteria, } \\
\text { Desulfovibrio cavernae }\end{array}$ \\
\hline
\end{tabular}

A low-resolution spectrum in the form of a color-color diagram of an exoplanet is likely to be one of the first post-detection quantities to be measured for the case of direct detection. Authors explore potentially detectable surface features on rocky exoplanets and their connection to and importance as a habitat for extremophiles, as known on Earth. Extremophiles provide us with the minimum known envelope of environmental limits for life on our planet. The color of a planet reveals information on its properties, especially for surface features of rocky planets with clear atmospheres. Filter photometry in the visible has been applied as a first 
step in the characterization of rocky exoplanets to prioritize targets for follow up spectroscopy. Many surface environments on Earth have characteristic albedos and occupy a different color space in the visible waveband ( 0.4 to 0.9 micron) that can be distinguished remotely. These detectable surface features can be linked to the extreme niches that support extremophiles on Earth and provides a link between geomicrobiology and observational astronomy. Such a method explores how filter photometry can serve as a first step in characterizing Earth-like exoplanets for an aerobic as well as an anaerobic atmosphere thereby prioritizing targets to search for atmospheric biosignatures. Below corresponding color-color diagrams from the cited work are presented.

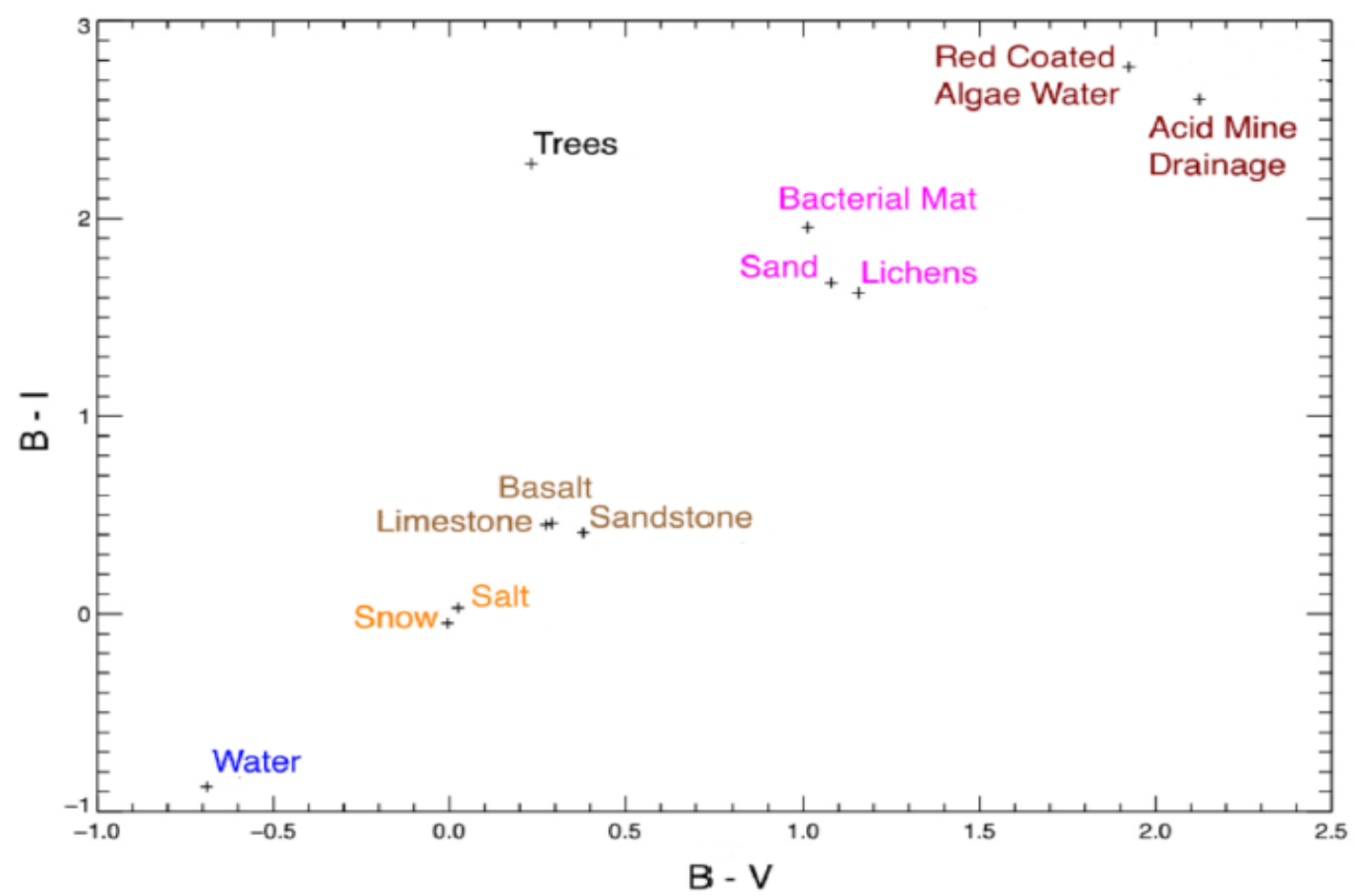

Figure 19.Colors of different species as observed by reflection spectra of the Earth (Hegde, Kaltenegger, 2013).

\section{About Oxygen molecular gas in planetary atmospheres as a biomarker}

An interesting question is what are limits of oxygen content in the atmosphere to probably be of bio-organic origin. For example, biogenic $\mathrm{O}_{2}$ in the terrestrial atmosphere with the content of $>1 \%$ (up to 3-4 \%) was arrived about $2.4 \mathrm{Gyr}$ ago and this is a threshold value which is considered by specialists to distinguish between not- and bio-organic sources (Canfield 2005). The main source was cyanobacteria (blue-green algae) which in large amounts is arrived 2.7 Gyr ago and now contribute between 50 to $85 \%$ of all (Brocks et al. 1999). Also, interestingly, in the case when the source is ceased $\mathrm{O}_{2}$ will disappeared in about $8 \mathrm{Myr}$ (Leger et al. 1999). By the way, there is a possibility to reveal the oxygen content between 80 and $50 \mathrm{Myr}$ ago 
according to data from ancient amber in Fig. 25 (Landis et al. 1995, fromYabushita and Allen, 1997).

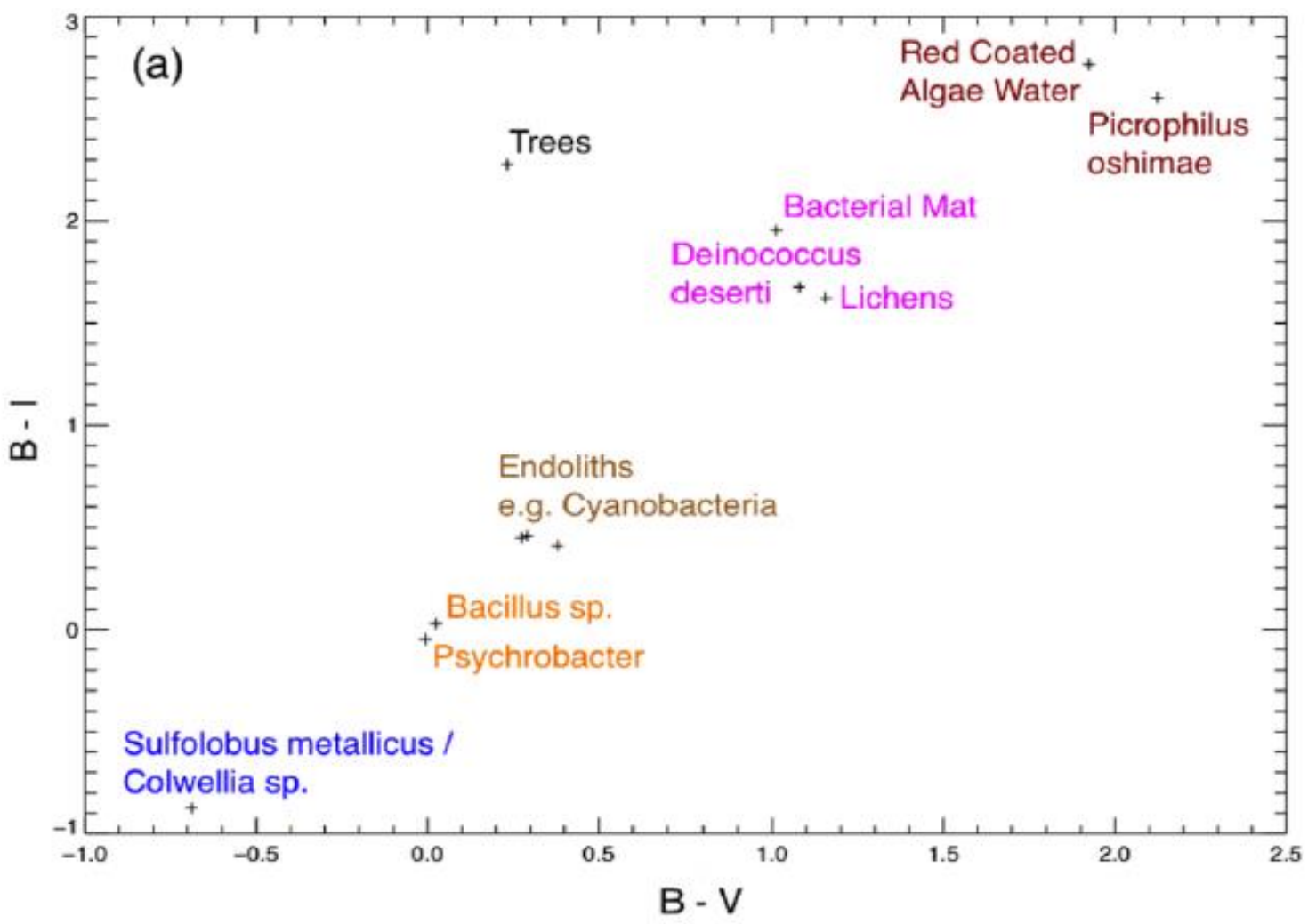

Figure 20.Surfaces supporting extremophiles for aerobic atmosphere (Hegde, Kartenegger 2013)

Exoplanets in the habitability zone have liquid water on the surface converting partly to vapor water. Depending on atmospheric transparency and the star's luminosity up to 3-4 \%of $\mathrm{O}_{2}$ is possible on the base of atmospheric photochemistry models (the process is stopped due to negative feedback via $\mathrm{O}_{3}$ ). But Selivanovsky and Domrachev (1999) have shown that a process known as a water sonolysis may arrange up to $20 \%$ of $\mathrm{O}_{2}$ in the terrestrial atmosphere.So one need a care observing oxygen in exoplanetary atmosphere without other biosignatures.

\section{Methane in the planetary atmosphere as a biosignature}

Methane in the terrestrial atmosphere with relative concentration $500-700 \mathrm{ppb}$ is clearly biogenic, also other big sources are volcano emission and forest fires. But methane was revealed also in the martian atmosphere about 5-10 ppb (Krasnopolsky et al. 2004). And the question is raised what does it mean because methane is observed in 3 different regions? Krasnopolsky et al. (2004)have connected observed methane with methanogenic bacteria but there is another explanation too (Yeghikyan et al. 2009) - methane has been delivered to Mars by comets and dust particles, buried and survived untill now to arrange the observed value via outgasing 
of rocks. One should recall that no tectonic motion on Mars are registered. The reason of our discrepancy is that we have considered also large comets (up to $10 \mathrm{~km}$ in diameters) and grazing trajectories while Krasnopolsky et al. (2004) only minor comets with diameters no more than $100 \mathrm{~m}$ and ignored grazing collisions(Keheyan et al. 2004).

Again one needs a care observing biosignatures in exoplanets when interpreting them as bioorganic: first of all one need to exlude all of the possible not bioorganic explanations.

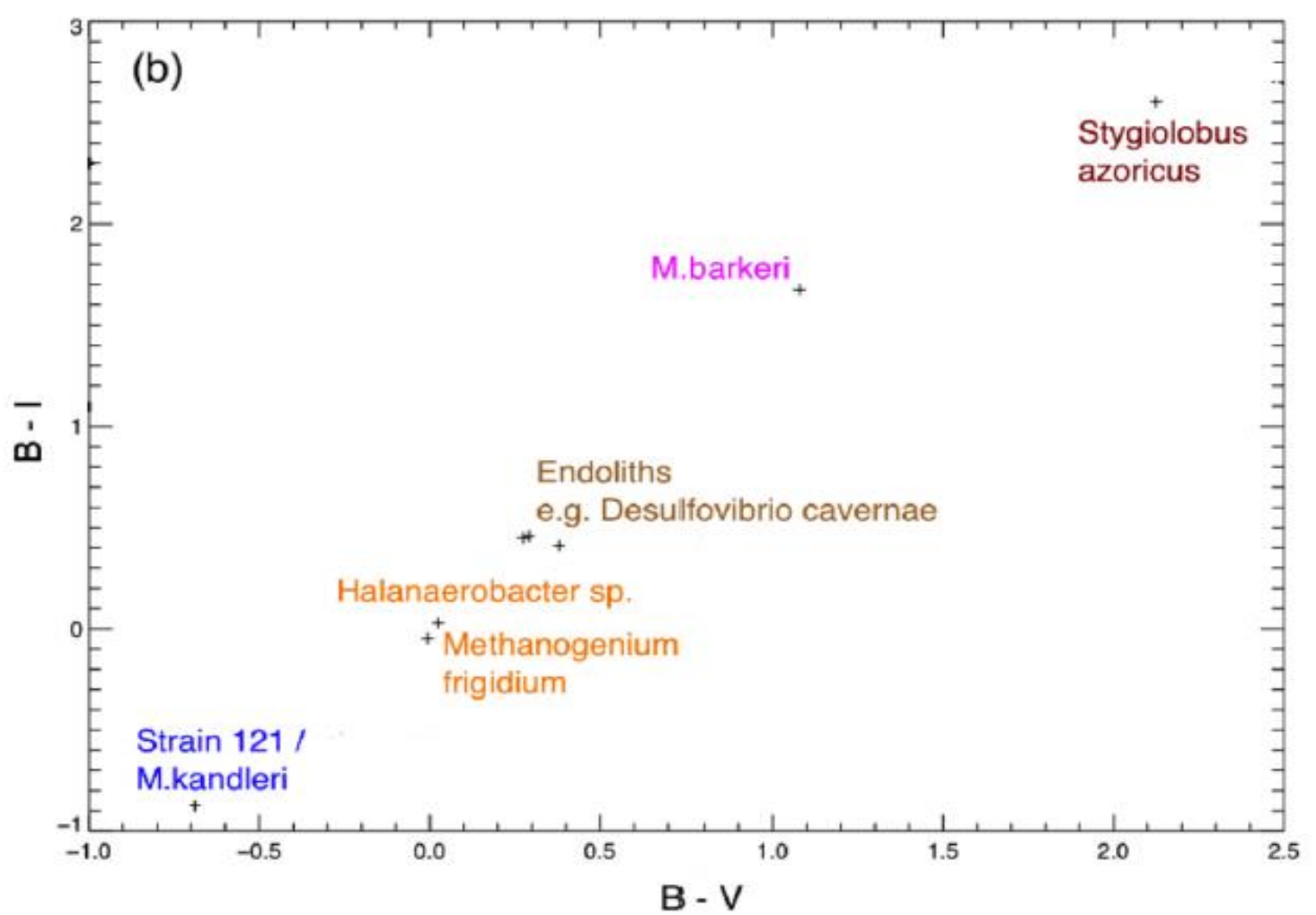

Figure 21.Surfaces supporting extremophiles for anaerobic atmosphere (Hegde, Kaltenegger 2013)

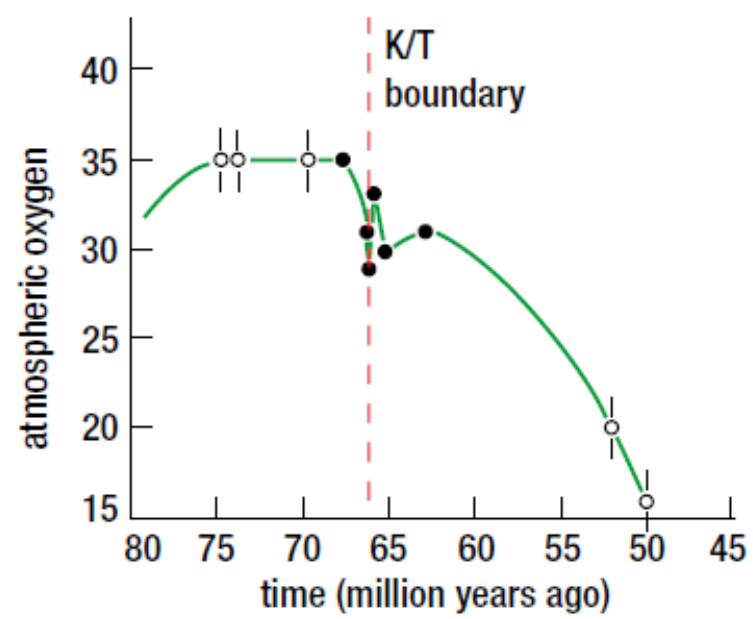

Figure 22.Variation of the $\mathrm{O}_{2}$ content of the terrestrial atmosphere contained in ancient amber. 


\section{The Galactic Habitable Zone}

Lineweaver et al. (2004) have presented an interesting diagram of probable habitability distribution in the Galaxy over the Hubble time. Constraints to the limits of habitability are quite reasonable: too many $\mathrm{SNe}$ in earlier time close to the Galactic centre and too metal poor in distante regions. Also for modern times close to the centre situation is too metall rich and for distante regions is too little time.One may present some additional points supporting this diagram (Yeghikyan 2015).

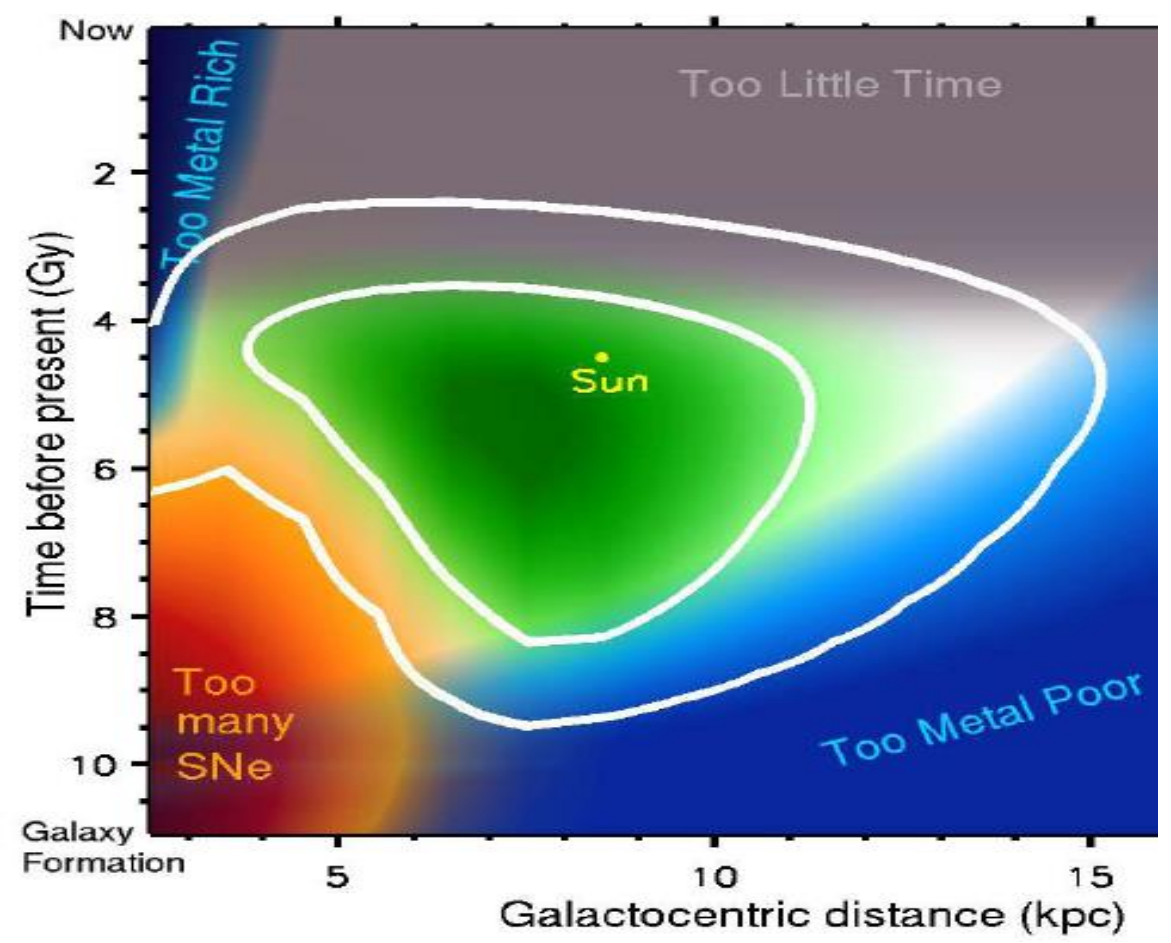

Figure 23. The Galactic habitable zone (Lineweaver et al. 2004)

The case is that the End of first 6-7 Gyr after the Big Bang is stand out in many points, not only already mentioned. These are segregation of thick and thin disks, amount of stars and clouds collisions, contribution into the ISM dust by SN versus AGB stars with different chemical structure, and clumping nature of dark matter, affecting all of the above ! For all such processes corresponding time-scales are about of 6-7 Gyr ago. One came to the conclusion that Life on the our planet (connected with the Sun) is one of the first among all possible!

\section{Conclusion}

Life on the Earth is the final product of a very long chemical evolution of matter, mainly under extraterrestrial conditions. This evolution started from the creation of the simplest molecules, survived sometimes under very hard conditions, condensed 
when possible into dust, begin to be covered with ice and making ice mantles of dust grains. Further, the radiation-chemical polymerization of a mixture of ices resulted with the formation of amino acids, sugars and hydrocarbons. It should be emphasized that these compounds should have been optically active, which distinguishes living organisms from inanimate ones. Delivery of these substances before the birth of life on Earth is a separate problem: most likely they were brought by comets, colliding with the Earth on grazing trajectories during the bombardment of the Earth between 4.5 and 3.8 billion years ago. There is the widely accepted point of view that Life on the Earth has originated 3.8 Gyr ago.

Biosignatures on the exoplanets in the first place are atmospheric gases like water, oxygen and methane, and then, possibly, some microorganisms for which existing color-color diagrams may be used.

At last but not least known galactic habitability zone is presented and additional data supporting an idea that the end of first 6-7 Gyr is stand out for the origin of life also are listed.

One can conclude that «Astrobiology is a branch of astrophysics on the base of a multidisciplinary study of subjects related to the origin, evolution, distribution and extinction of life as well as to its detection in the universe» (by IAU Commission 51). At last but not least, astrobiology demand on the close cooperation between specialists of all the appropriate disciplines.

\section{References}

Beltrán, M., Codella, C., Viti, S., Neri, R, ,Cesaroni, R.2009, ApJL, 690, 93

Blank, J., Miller, G. 1997, Inter. SympShock Waves 21st, 1-6.

Brocks, J., Logan, G., Buick, R., Summons,R., 1999, Science, 13:285 (5430), 10331036Brook,s J., Shaw, G. 1973, Origin and Development of Living Systems, London.

Campbell, N., Rees, J., Urry, L. et al., 2010, Biology, Pearson Education, SF, 507

Canfield, D. 2005, Ann. Rev. Earth Planet. Sci. 33,

Deamer, D. et al. 2002, Astrobiology, 2, 371

Delsemme, A. 1997, CometaryOrigine of the Biosphere, in: Comets and the Origin and Evolution of Life, P. Thomas, F. Chyba, C. McKay, eds.,29-65, Springer.

Ehrenfreund, P., Irvine, W., Becker, L.et al.,2002,Rep. Prog. Phys., 65, 1427

Fraser, H., McCoustra, M., Williams, D. 2002, Astronomy \& Geophysics, 43, 10

Gold, T.The Deep Hot Biosphere, Springer, 230 pages

Greenberg, J., Li, A. 1999, Space Sci., 47, 787

Haldane, J. B. S., 1929, in "The Origin of Life" ed. Bernal London, Weidenfeld and Nicolson p. 242-249

Hegde, S.,Kaltenegger, L. 2013, Astrobiology, 13, 46 
Kagramanov, Yu.,Yeghikyan, A. 2000, Oil Gas Geol., N5, 53

Keheyan, Y., Cataldo, F., Yeghikyan, A. 2004, Astrophysics. 47, 422

Krasnopolsky, V., Maillard, J, Owen, T. 2004, Icarus, 172 (2), 537

Kuan, Y., Charnley, S., Huang, H., Tseng W., Kisiel, Z. 2003, ApJ. 593, 848

Kwok, S.2000, The Origin and Evolution of Planetary Nebulae, CUP, Cambridge, 255 pages.

Kwok, S. 2011, OLEB, 41, 497

Léger, A., Ollivier, M., Altwegg, K., Woolf, N. 1999, A\&A, 341, 304

Lewis, J., Prinn, R. 2010, Planets and their atmospheres, CUP, 520 pages.

Lineweaver, C, Fenner, Y., Gibson, B. 2004, Science, 303 (5654), 59

McCarthy, E., Calvin, M. 1967, Nature, 216, 642

McGuire, B., Caroll, P., Loomis, R., Finneran, I., Jewell, P., Remijan,A., Blake, G., 2016, Science,352, (6292), 1449

Mauerette, M., 2006, Micrometeorites and the Misteries of our Origin, Springer, 452 pages.

Meierhenrich, U. 2008, Amino Acids and the Asymmetry of Life, Springer, 254 pages

Muller, H., Scholder, F., Stutzki, J., Winnewisser, G. 2008, J. Mol. Struct.742, 215-235, www.astro.uni-koeln.de/cdms/molecules

Oparin, L. 1924, TheOrigine of Life, 1938, The Macmillan Comp., New York. (eng. trans.)

Pearce, B., Pudritz, R. 2015, ApJ. 807, 85

Pierazzo, E., Melosh, H. 2000, Ann. Rev. Earth, Planet. Sci., 28, 141

Selivanovsky, D., Domrachev, G. 1995, J. Acoustic Soc. America,Sonolysis in liquid water without gas bubbles 98, 2981, 5

Sparks, W., Houghb, J. Germerc, T., et al. 2009, PNAS, 106 (19), 7816

Sverdlov, L.M., Kovner, M.A., Kraynov, E.P, 1979, Nauka, M.,.562 pages

Svetsov, 2002, Assessment of Organics Delivery by Comets to the Early Earth, Lunar Planet., Sci., XXXIII

Williams ,D., Viti S. 2013, Observational Molecular Astronomy, CUP, 192 pages

Yabushita, S., Allen, A. 1997, Astronomy and Geophysics, 38 (2), 15

Yamamoto, S. 2017, Introduction toAstrochemistry, Springer, 2017, 293 pages

Yeghikya, A. 2017, Molecular Astrophysics, 8, 40

Yeghikyan, A. 2017, ASP Conf. Ser. 511, 98

Yeghikyan, A. 2017, The Origin of Life from the Astrophysical Point of View, in: The First Joint International Conference on Astrophysics for Young Scientists, St.Petersburg, 3-9

Yeghikyan, A. 2016a, ASP Conf. Ser., 505, 144 
Yeghikyan,A.2016b, Irradiation of ices inside molecular clouds in cosmic ray dominated regions of galaxies, in: Eds. A. Mickaelian, H.Khosroshahi, H. Harutyunian. Yerevan, "Gitutyun"National Academy of Sciences of the Republic of Armenia (NAS RA), p. 162

Yeghikyan, A. 2015, in "Relation of Astronomy to other Sciences, Culture and Society" Proceedings of XIII Annual Meeting of Armenian Astronomical Society, held 7-10 October 2014 in Byurakan Astrophysical Observatory, Armenia. Eds.: H. A. Harutyunian, A. M. Mickaelian, S. V. Farmanyan; Yerevan, "Gitutyun" Publishing House of the National Academy of Sciences of the Republic of Armenia (NAS RA), 72 Yeghikyan, A. 2013a, Astrophysics, 56, 142

Yeghikya, A. 2013b, ARAS News, 64, 8-11.

Yeghikyan, A. 2011a, Astrophysics, 54,87

Yeghikyan, A. 2011b, ISRN Astronomy and Astrophysics, vol. 2011, id.905015

Yeghikyan, A. 2010, in: "Evolution of Cosmic Objects through their Physical Activity", Proceedings of the Conference dedicated to Viktor Ambartsumian's 100th anniversary, held 15-18 Sep 2008 in Yerevan and Byurakan, Armenia, Editors: H.A. Harutyunian, A.M. Mickaelian and Y. Terzian, Yerevan, "Gitutyun" Publishing House of NAS RA, p. 70

Yeghikyan, A. 2009, Astrophysics,52, 288

Yeghikyan, A. 2008, Astrophysics and Space Sciences Transactions, 4 (2), 47

Yeghikyan, A., Barsamyan L.2013, On dust irradiation in molecular clouds IV.ACR doses, 56, 443

Yeghikyan, A., Fahr, H., 2006,in: "Solar Journey: The Significance of our Galactic Environment for the Heliosphere and Earth", Edited by Priscilla C. Frisch, University of Chicago, IL, USA. Astrophysics and Space Science Library, Vol. 338. Springer Dordrecht, 317

Yeghikyan, A., Fahr, H. 2004b, A\&A, 425, 1113

Yeghikyan, A., Fahr, H. 2004a, A\&A, 415, 763

Yeghikyan, A., Fahr, H.C2003, Annales Geophysicae, 21 (6), 1263

Yeghikyan, A., Viti S., Williams, D. 2001, Mon. Not. R. Astron. Soc., 326, 313

Yeghikyan, A., Brutyan A., Melkonyan S.2009,Does methane in the martian atmosphere comes from methanogenic bacteria? Ann. Meeting of the Armenian Astronomical Society, Byurakan, July 6-8.

Zhukowska, S. 2008, Dust formation by stars and evolution of the ISM, PhD theses, Heidelberg

Zwicker, D., Seyboldt, R., Weber, C., Hyman, A., Jülicher, F., 2017, Nature Physics, 13, 408 